\title{
Bau und Lebensgeschichte des Polypen von Tripedalia cystophora (Cubozoa, class. nov., Carybdeidae) und seine Bedeutung für die Evolution der Cnidaria
}

\author{
B. WERNER \\ Biologische Anstalt Helgoland (Zentrale); Hamburg 50, \\ Bundesrepublik Deutscbland
}

\begin{abstract}
Structure and life history of the polyp of Tripedalia cystophora (Cubozoa, class. nov., Carybdeidae) and its importance for the evolution of Cnidaria. Following HAECKEL (1880), most zoologists have grouped the Cubomedusae with the class Scyphozoa. However, the actual systematic position and evolution of the Cubomedusae remained unclear because essential phenomena of the life cycle, i. e. life history and structure of the polyp generation and the process of medusa formation were unknown. Successful cultivation of the Carribean larviparous Tripedalia cystophora CONANT, 1898 elucidated for the first time the complete life cycle of a cubomedusa. Primary polyps could be raised from planulae which were transferred by air mail from La Parguera, Puerto Rico. The sessile polyp is solitary. Its morphology, anatomy, and behaviour are described. The body (length $0.6-1.0 \mathrm{~mm}$ ) is radially constructed without any trace of tetramerous structures, 6 to 11 solid capitate tentacles insert in one circle, above which the body ends in a long contractile snout-like mouth cone (proboscis). The body is sac-like without gastric septa or gastric pockets; its base is enveloped by a small cup of thin, structureless periderm. Asexual reproduction by which the stock is enlarged quickly envolves lateral budding of small secondary polyps. After detachment these small polyps go through a creeping phase. The fully grown polyp shows a remarkable behavioural plasticity as it can migrate and change into an inactive encysted stage. The whole polyp metamorphoses into a single medusa. All externally visible metamorphosis phases are described. First, the polyp's body becomes tetramerous due to 4 longitudinal folds. The tentacles congregate into 4 groups, each in one quadrant. While the distal parts of the tentacles are resorbed, their bases develop into 4 perradial sensory organs (rhopalia). Interradially, 4 new tentacles are formed and become the primary tentacles of the medusa. Simultaneously, the complete body of the polyp transforms into the bell of the medusa. At the end of the metamorphosis which takes 5 to 6 days at 25 to $27^{\circ} \mathrm{C}$, the young medusa begins to pulsate quidkly and swims away leaving behind the empty peridermal cup. The morphology of the young medusa is described. T. cystophora has a tricnidom of basitrich haplonemes, holotrich haplonemes, and heterotrich microbasic euryteles. The ecology of both, polyp and medusa generation, is briefly outlined. A critical comparison between the polyp and medusa of $T$. cystophora and the Scyphozoa and Hydrozoa reveals important differences. Consequently, a new class, $\mathrm{Cu}$ bo $\mathrm{z} o \mathrm{a}$, must be established and given the evolutionary position between Scyphozoa and Hydrozoa. Diagnoses are presented for the polyp of $T$. cystophora and the class Cubozoa.
\end{abstract}




\section{EINLEITUNG}

Die Cubomedusen sind Bewohner der tropischen Meeresgebiete, wo sie in den neritischen Zonen stellenweise sehr häufig sind. Thre Hauptverbreitungsgebiete sind der Indopazifik (Philippinen, Ostküste von Australien) und das Karibische Meer. Die nördliche Verbreitungsgrenze wird in der östlichen Hemisphäre von Carybdea rastoni an der Südwestküste von Hokkaido, in der westlichen Hemisphäre von Carybdea marsupialis im Mittelmeer erreicht (UchIDA, 1954; Kramp, 1961). Durch ihre intensive Nesseltätigkeit sind mehrere Arten an den Stellen ihres häufigen Vorkommens als „sea wasps" berühmt und berüchtigt. Das Nesselgift von zwei indopazifischen Arten, Chiropsalmus quadrigatus und besonders Chironex fleckeri, ist so gefährlich, daß es bei empfindlichen Personen und Jugendlichen den schnellen oder plötzlichen Tod durch Lähmung des Atem- und Kreislaufzentrums herbeiführen kann (Cleland \& SouTHCOTT, 1965, BARNES, 1966).

Die Cubomedusen („box jellies") haben ihren Namen von der angenäherten Würfelform ihres Schirms, der die tetramere Anordnung und Ausbildung aller wesentlichen Organe entspricht. Die erste Art wurde von Linné (1758) als Medusa marsupialis (= Carybdea marsupialis) beschrieben. Seit HaEcKel (1880) wird diese Gruppe stets zu den Scyphomedusen gerechnet. Indes haben kritische Autoren (Claus, 1883; MAYER, 1910; OKADA, 1927) mehrfach darauf hingewiesen, daß diese Einordnung wegen der erheblichen Unterschiede gegenüber den anderen Scyphomedusen (Coronatae, Semaeostomeae, Rhizostomeae) sehr problematisch sei, so daß die Cubomedusen zumindest eine aberrante Gruppe darstellten.

Die eigenen Untersuchungen über die Lebensgeschichte der Cubomedusen nahmen ihren Ausgang von den Untersuchungen über Stephanoscypbus (Scyphozoa, Coronatae). Sie hatten ergeben, daß dieser Polyp ein lebendes Fossil und "missing link“ ist und daß er eine Schlüsselstellung für die Aufklärung der evolutionistischen Entwicklungslinien innerhalb der Klasse Scyphozoa und des gesamten Stammes Cnidaria einnimmt (WERNER, 1966, 1967, 1970, 1971, 1973b). Insbesondere hatte der Vergleich mit dem Scyphistoma, dem Polypen der Medusenordnungen Semaeostomeae und Rhizostomeae, gezeigt, daß Stephanoscyphus ebenso wie die von ihm erzeugten Coronatenmedusen Merkmale einer primitiveren Organisation aufweist. Die Untersuchung der Feinstrukturen hatte dieses Ergebnis bestätigt (CHAPMAN \& Werner, 1972). Stephanoscyphus steht daher der gemeinsamen Stammform aller rezenten Scyphozoen näher als der Scyphistoma. So ergab sich die Schlußfolgerung, daß die Coronatae die Basisgruppe der Scyphozoa darstellen. Demgegenüber hatte Uchids (1969) die Ansicht vertreten, daß dieser Rang der Ordnung Cubomedusae zuerkannt werden müsse, weil bei ihnen der für die gesamte Klasse so charakteristische tetramere Bauplan am deutlichsten ausgeprägt sei.

Diese Auffassung war nicht einwandfrei zu begründen, sie konnte aber auch nicht widerlegt werden, solange die Lebensgeschichte der Cubomedusen nicht restlos aufgeklärt war. Die entscheidende Lücke war die Unkenntnis des erwachsenen Polypen und der Phasen der Medusenbildung, während Bau und Systematik der Medusen als hinreichend bekannt gelten konnten, was andererseits weniger für ihr Verhalten und ihre Lebensweise zutraf. Zwar hatten bereits zwei frühere Autoren, CONANT (1898) 
und OKaDA (1927), Planulae von Cubomedusen zur Anheftung am Substrat gebracht und ihre Entwicklung zu Primärpolypen beobachtet; doch war beiden die Aufzucht zu erwachsenen Polypen nicht gelungen.

ConAnT, dem wir eine ausführliche Beschreibung der Morphologie und Anatomie der Cubomedusen und die Erstbeschreibung von Tripedalia cystophora verdanken, hat im Karibischen Meer (Jamaica) auch die Larviparie dieser Art beobachtet, auf die ihr Speciesname hinweist. Die Eier entwickeln sich in den Gastraltaschen der weiblichen Meduse zu Planulae, die anschließend ausgestoßen werden und sich nach einer kurzen planktischen Phase von 1 bis 2 Tagen anheften und in Jungpolypen umwandeln. Die Weiterentwicklung wurde nicht beobachtet. Der Originalbericht ist in mehrfacher Hinsicht von besonderem Interesse, so $\mathrm{da} ß$ er im Wortlaut wiedergegeben werden muß;

"The embryos were thrown out in the aquaria as free-swimming planulae, which settled down on the bottom and sides of the glass in a day or two, and quickly developed into small hydras with mouth and typically with four tentacles (and four taenioles, W. K. B.)" (Conant, 1898; p. 23). Bemerkenswert ist einmal, daß die Jungpolypen als „hydras" bezeichnet werden und nicht als Scyphistomae, zum anderen, daß ihnen nicht vom Autor ConANT, sondern vom Herausgeber W. K. Brooks - nur auf diesen können sich die Anfangsbuchstaben beziehen - Taeniolen, das heißt Gastralsepten zugeschrieben werden. Offenbar wurde dieses Merkmal weder vom Autor noch vom Herausgeber realiter beobachtet, von letzterem aber nach dem frühen Tode ConanTs in der selbstverständlichen Annahme zugefügt, daß Tripedalia zu den Scyphomedusen zu rechnen sei, daß ihr Polyp also wie der Scyphistoma tetramer gebaut und im Besitz von 4 Gastralsepten sei. Diese, wie sich zeigen wird, irrtümliche Annahme ist später mehrfach in die Literatur eingegangen. So übernimmt MAYER (1910) die oben zitierten Befunde und beschreibt die Jungpolypen von Tripedalia bereits als „... small Scyphostomae with mouth and typically with 4 tentacles and 4 taeniolae..." (p. 514). Dabei muß diesem Autor zugute gehalten werden, worauf schon kurz hingewiesen wurde, $\mathrm{daß}$ er in der Einleitung zur Darstellung der Klasse Scyphomedusae die aberrante $\mathrm{Na}$ tur der Cubomedusen ausdruicklich hervorhebt: "The Carybdeidae are so aberrant and our knowledge of their development is so imperfect that we have not yet been able to determine their relationships to other Scyphomedusae" (p. 500). Die gleichen Angaben über den Bau des Polypen von Tripedalia finden sich auch in der späteren Literatur wieder, so etwa bei KRUMBACH (1924; p. 573), obwohl auch er an anderer Stelle (p. 570) erwähnt, daß die Ontogenie der Cubomedusen wie zu Haeckels Zeiten noch immer ungeklärt sei.

Die Untersuchungen von OKADA (1927) über die Entwicklungsgeschichte von Carybdea rastoni brachten den großen Fortschritt, daß die Phasen der Frühentwicklung nämlich die Eifurchung, die Entstehung des Entoderm durch Delamination und Zellteilung der bereits ins Blastocöl eingewanderten Zellen sowie die Entwicklung bis zur Planula aufgeklärt werden konnten. Angaben über die Dauer der planktischen Periode fehlen; doch haben die Wimperlarven auch bei dieser larviparen Art offenbar nur eine sehr kurze planktische Phase. Sie hefteten sich in der üblichen Weise am Substrat an und wandelten sich innerhalb von 1 bis 2 Tagen in Primärpolypen mit 2, oft mit 3 Tentakeln um. Interessanterweise nennt auch dieser Autor den Jungpolypen „... un jeune Hydroide ..." (p. 244), auch wenn er in Fig. I (p. 243) die „... Transformation 
de la planula en scyphistome..." illustriert. Ebenso erwähnt er an anderer Stelle (p. 247), daß die Suche nach dem Scyphistoma an den Orten, an denen die Meduse häufig war, vergeblich gewesen sei. Die kleinen Primärpolypen blieben mehrere Wochen am Leben, ohne sich weiter zu entwickeln. Vermutlich starben sie an Nahrungsmangel. Die bildliche Darstellung kann verständlich machen, daß OKADA das von ihm beobachtete Stadium einen jungen Hydroiden genannt hat; denn es gleicht einem jungen Hydroidpolypen in der Tat weit mehr als einem jungen Scyphistoma (Abb. 1).

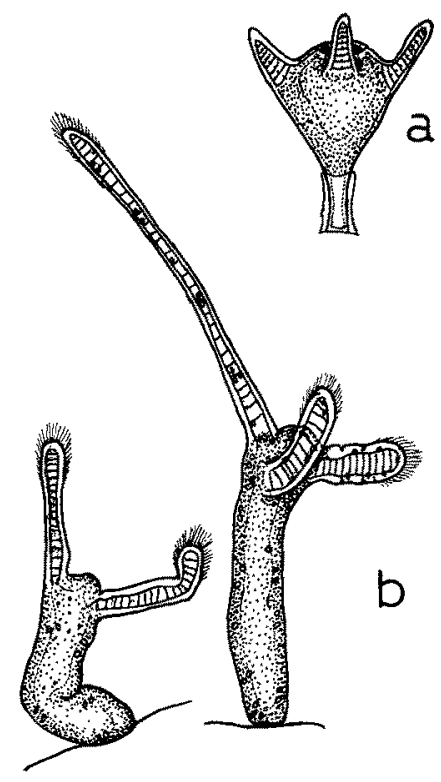

Abb. 1 a, b: Primärpolypen kurz nach der Umwandlung aus Planulae, a der Scyphomeduse Chrysaora spec. (nach Cuaus, 1883; Textfig. c, p. 6); b der Cubomeduse Carybdea rastoni (nach OKADA, 1927; Fig. I, e, f, p. 243. Zeichnungen geringfügig verändert)

Auch in der neueren Literatur wird auf die alten Befunde Bezug genommen; offenbar steht UcHIDA (1969, p. 248) unter ihrem Einfluß, wenn er erwähnt, daß sich die Planula der Cubomedusen zu einem Scyphopolypen entwickelt.

Daß ein $\mathrm{Cubopolyp}$ bis vor kurzem im freien Meer nicht gefunden wurde, hat wahrscheinlich mehrere Gründe. Einmal müssen die weiten Küstengebiete der tropischen Meere auch heute noch als weitgehend unerforscht oder können höchstens als lückenhaft erforscht gelten. Es kann keinem $Z$ weifel unterliegen, daß die intensive und gezielte Suche nach einem Cubopolypen in den Gegenden des Massenauftretens der Medusen zum Erfolg führen würde. Andererseits muß zugegeben werden, daß die Suche vermutlich sehr mühsam und zeitraubend und wohl auch von Glückszufällen abhängig sein dürfte. Außerdem sind die Cubopolypen sehr wahrscheinlich allgemein von geringer Größe, wie nach den eigenen Beobachtungen über den Polypen von Tripedalia anzunehmen ist. 
In jedem Fall war nach den Resultaten der Untersuchungen ConanTs (1898) und Okadas (1927) an der Existenz einer Polypengeneration bei den Cubomedusen nicht $\mathrm{zu}$ zweifeln. So erschien für den eigenen Versuch, endlich die Lebensgeschichte dieser rätselhaften Gruppe aufzuklären, der von diesen Autoren beschrittene Weg, den Polypen aus Planulae zu züchten, von vornherein als der einfachere. Er bot sich einmal deswegen an, weil es wie erwähnt larvipare Arten gibt; daher besteht die Möglichkeit, relativ leicht größere Mengen ihrer Planulae zu erhalten; dann aber auch aus dem Grunde, weil die Chancen, auch kleine und empfindliche Entwicklungsstadien zur Weiterentwicklung zu bringen, heute durch die Anwendung moderner Kulturmethoden ungleich größer sind als früher. Die larvipare Art Tripedalia cystophora, die nach den alten Angaben von CoNANT (1898) an der Küste von Jamaica sehr häufig war, erschien nach allem als die am meisten Erfolg versprechende Form. Bei der brieflichen Erkundung im Jahre 1970, ob diese Art im Karibischen Meer auch heute noch in ausreichenden Mengen anzutreffen sei, hatte ich das große Glück, mit Herrn Prof. Ch. Curress (Department of Marine Sciences, University of Mayagüez, Puerto Rico, USA) Verbindung aufnehmen zu können, der mit seinen Mitarbeitern ein langfristiges Programm zur Erforschung der Medusenfauna der Küstengewässer von Puerto Rico in Angriff genommen hatte. Dieses Programm galt speziell auch den Cubomedusen, die dort durch ihr zeitweilig häufiges Auftreten den Badebetrieb empfindlich stören, so daß ein öffentliches Interesse an der Untersuchung ihrer Lebensgeschichte, ihrer Okologie und der Fluktuationserscheinungen bestand. Von Herrn Cutress erhielt ich alle notwendigen Auskünfte; er teilte mir mit, daß Tripedalia in den Mangrovegürteln nahe der zugehörigen Meeresstation La Parguera häufig ist und ging auch bereitwillig auf meinen Wunsch ein, mir auf dem Luftwege lebende Planulae dieser Art zu schicken.

Der Versuch verlief im Juli 1970 erfolgreich. Die Planulae überstanden den Lufttransport, und es gelang, sie zum Ansatz und zur Umwandlung in die winzigen Primärpolypen zu bringen, die bis zur vollen Größe weitergezüchtet werden konnten. So war es bis Ende 1970 möglich, den Polypen auf seine Morphologie und Organisation zu untersuchen, seine asexuelle Vermehrung durch Polypenknospen und alle Stadien der Medusenbildung zu beobachten. Schließlich gelang es in der Folgezeit, auch die Jungmedusen bis zur vollen Größe und Geschlechtsreife aufzuziehen. Damit war erstmals der vollständige Lebenszyklus einer Cubomeduse aufgeklärt, und das letzte große Rätsel in der Kenntnis der Lebensgeschichte der Cnidaria war endlich definitiv gelöst. Die Ergebnisse wurden in einer vorläufigen Mitteilung gemeinsam publiziert (WERNER et al., 1971; vgl. WERNER, 1973b).

Das wesentliche, völlig unerwartete Ergebnis war, daß der Polyp von Tripedalia keinerlei Ahnlichkeit mit einem Scyphopolypen besitzt, daß er vielmehr in allen entscheidenden Merkmalen sowohl von Stephanoscypbus, dem Polypen der Coronatae, wie auch vom Scyphistoma der Semaeostomeae und Rhizostomeae grundverschieden ist. Radialsymmetrischer Bau des Körpers, Fehlen aller tetrameren Strukturen, also von Gastralsepten, Gastraltaschen, Septalmuskeln, damit einfacher sackförmiger Bau des Körpers ohne innere Gliederung, Vorhandensein capitater Tentakel, asexuelle Vermehrung durch seitliche Polypenknospung ähnlich wie beim Süßwasserpolypen Hydra, endlich vollständige Metamorphose des Polypen in eine und nur eine Meduse, ohne daß ein basaler Restkörper zurückbleibt: Alle diese Merkmale geben dem Polypen von 
Tripedalia eine Sonderstellung, durch die er sich aus der Klasse Scyphozoa eindeutig heraushebt. Andererseits besteht auch, wie später zu zeigen sein wird, eine deutliche Abgrenzung zu den Hydrozoa. Die systematische und evolutionistische Konsequenz, die $\mathrm{Cuboz}$ o a in den Rang einer Klasse zwischen den Scyphozoa und Hydrozoa zu erheben, ist in kurzer Form bereits erörtert worden (WERNER, 1973b). Wie dort angekündigt, bedarf dieser Schritt noch der ausführlichen Begründung durch die eingehende Beschreibung des Baues und der Lebensgeschichte des Polypen sowie auch besonders der Art der Medusenbildung.

Es ist von großer Bedeutung, daß es in Puerto Rico gelungen ist, den Lebenszyklus einer weiteren Cubomedusenart aufzuklären. Dort war im Jahre 1970 von Prof. CutRess auf dem Meeresboden in geringer Tiefe zwischen den Mangrove-Inseln bei La Parguera ein kleiner unbekannter Polyp entdeckt worden, der an Muschelschalen angeheftet war. Er wurde in Kultur genommen und konnte in der Folgezeit auf Grund der Kenntnis des Polypen von Tripedalia ebenfalls als Cubopolyp identifiziert werden. Anfangs wurde die neue Form als Polyp der Art Tripedalia cystophora selbst angesehen; doch ergaben Korrespondenz und weitere Untersuchungen über die Strukturmerkmale des Polypen und der aus ihm entstandenen Meduse, daß es sich um eine andere Art handeln mußte. Es zeigte sich bald, daß der Polyp eine Meduse des Genus Carybdea erzeugt. Die vorläufigen Ergebnisse sind von Cutress in einem nicht publizierten Bericht niedergelegt, der mir zugänglich gemacht wurde (CH. E. Cutress: Investigation of the biology and control of noxious Coelenterates occurring in the coastal waters of Puerto Rico. Second Ann. Rep., Fish. Developm. Program, Dep. of Agricult., Commonwealth of Puerto Rico, Mayagüez, January 1971). Die weiteren Untersuchungen waren Thema einer Thesis von F. J. STUdebakeR, deren Veröffentlichung abzuwarten bleibt. Der Lebenszyklus der in Puerto Rico untersuchten Art Carybdea spec. stimmt in allen wesentlichen Punkten mit dem von Tripedalia überein, wenn auch der Polyp von Carybdea in einigen Merkmalen, wie Größe, Tentakelzahl, Begeißelung, Cnidom genus-spezifische Unterschiede aufweist.

Im folgenden werden die allgemeinen Beobachtungen über die Entwicklung, die Morphologie und Anatomie, die asexuelle Vermehrung und die Metamorphose des Polypen von Tripedalia cystophora mitgeteilt und illustriert, der seit $1970 \mathrm{im}$ Laboratorium gezüchtet wird. Da es gelungen ist, die Medusen nicht nur bis zur Geschlechtsreife heranzuziehen, sondern sie auch zur Fortpflanzung $z u$ bringen, so daß die $F_{1}$ Polypengeneration existiert, darf angenommen werden, daß die hier mitgeteilten $\mathrm{Be}$ funde allgemeine Gültigkeit haben, auch wenn sie sich ausschließlich auf Kulturmaterial beziehen. So braucht nicht befürchtet zu werden, daß mit anderen Ergebnissen zu rechnen ist, wenn es gelingen sollte, den winzigen Polypen im natürlichen Biotop aufzufinden. Das muß deswegen erwähnt werden, weil es ja jetzt auch erstmals möglich ist, die Artdiagnose eines Cubopolypen mitzuteilen.

Auf meine Bitte hat es Herr Prof. D. M. Chapman (Halifax, Canada) übernommen, die Histologie des Polypen mit Anwendung elektronenoptischer Methoden zu bearbeiten. Ein kurzer gemeinsamer Beitrag enthält die ersten Ergebnisse über das Muskel- und Nervensystem des Polypen von Tripedalia (Werner \& Chapman, im Druck). Die ausführliche Darstellung der Resultate über die Feinstrukturen des Polypen von Tripedalia durch CHAPMAN ist in Vorbereitung. Die anatomischen und histolo- 
gischen Phänomene der Metamorphose des Polypen in die Meduse werden zur Zeit untersucht und später mitgeteilt.

\section{MATERIAL UND METHODE}

Die einleitende Darstellung der Vorgeschichte hat deutlich gemacht, daß sich alle Anstrengungen auf die Aufzucht der jungen Primärpolypen konzentrieren mußten, wenn das angestrebte Ziel erreicht werden sollte. Die Planulae wurden am 20. 7. 1970 von Puerto Rico in 2 Thermosflaschen von je $500 \mathrm{ml}$ Inhalt abgesandt, die etwa zur Hälfte gefüllt waren, und kamen am 22. 7. 1970 in Hamburg an. Die Oberflächentemperatur des Meeres im Mangrovegürtel von La Parguera, wo die Muttermedusen gefangen waren, betrug $29^{\circ} \mathrm{C}$; doch war das filtrierte Seewasser, in dem die Planulae auf die Reise geschickt wurden, vorher gekühlt und hatte bei der Ankunft eine Temperatur von $19^{\circ} \mathrm{C}$. Der Salzgehalt betrug $37 \%$.

Es zeigte sich, daß die Planulae bei der Ankunft bereits die Schwimmfähigkeit verloren und sich an den Innenwänden der Thermosflaschen angeheftet hatten. Durch vorsichtiges Abspülen mit einer Pipette konnten sie abgelöst werden und wurden dann in frisches Seewasser umgesetzt. Das war deswegen ohne Beschädigung der winzigen Stadien (Durchmesser $0,13 \mathrm{~mm}$ ) möglich, weil sie sich beim Anheften mit einer feinen Hüllmembran umgeben hatten. Sie wurden in 2 Gruppen bei $22^{\circ}$ und $28^{\circ} \mathrm{C}$ in natürlichem Seewasser weitergezüchtet, das von Helgoland stammte und dessen Salzgehalt auf einen annähernd konstanten Wert von 34,5\% eingestellt wurde. Die Embryonalstadien klebten am Boden der Kulturschalen erneut, das heißt passiv an. Daß sie den Transport gut überstanden hatten, zeigte sich nach wenigen Tagen, als ihre Entwicklung zu Primärpolypen mit 2 bis 4 Tentakeln einsetzte. Ihr Körper hatte den gleichen Durchmesser wie vorher die Planulae.

Bei ihrer geringen Größe war das entscheidende Problem die Ernährung. Frischgeschlüpfte Artemia-Nauplien, die eine Länge von etwa $0,5 \mathrm{~mm}$ haben, und selbst Teilstücke von solchen waren viel zu groß und wurden nicht angenommen. Das gleiche galt für fein zerzupfte Stückchen der Mitteldarmdrüse von Mytilus edulis. Protozoen geeigneter Größe, die wahrscheinlich die erste natürliche Nahrung der jungen Polypen im Meer darstellen, standen nicht schnell genug zur Verfügung. Als erfolgreich erwies sich schließlich die Methode, kleine Stückchen der Mitteldarmdrüse von Mytilus edulis mit spitzen Pinzetten zu zerquetschen und den erhaltenen feinkörnigen Zellbrei mit fein ausgezogenen Glasnadeln vorsichtig auf die Oberseite der Primärpolypen zu legen. Es zeigte sich bald, daß sie in der Lage waren, einen ihrer Größe entsprechenden Teil des weichen Zellbreis mit dem Mund aufzunehmen und zu verschlucken. Mit dieser zeitraubenden Methode der individuellen Fütterung gelang es, eine ausreichende Zahl von Primärpolypen nicht nur am Leben zu halten, sondern sie auch zum Wachsen zu bringen, bis sie groß genug waren, anfangs einen halben, später einen ganzen ArtemiaNauplius zu verschlucken. Dabei ist bemerkenswert, daß es bei einer Wassertemperatur von $28^{\circ}$ bzw. $22^{\circ} \mathrm{C}$ noch $1-2$ bzw. 2-3 Wochen dauerte, bis die Jungpolypen überhaupt mit der ersten Nahrungsaufnahme begannen.

Als Kulturschalen wurden anfangs flache Boverischalen von $50 \mathrm{ml}$ Inhalt benutzt, 
die die genaue Kontrolle und individuelle Fütterung unter dem Stereomikroskop bei stärkeren Vergrößerungen gestatten. Diese Schalen wurden später in größere eingesetzt, wodurch auch das Problem der zunächst täglichen, nur mit Vorsicht möglichen Wassererneuerung erleichtert wurde. Die Fütterung erfolgte anfangs jeden zweiten Tag, später täglich, bis die Bildung von Knospen einsetzte und die Primärpolypen in der Lage waren, sich von Artemia-Nauplien zu ernähren. Die Kulturen wurden dann in der üblichen Weise behandelt, daß zahlreiche Nauplien in die Kulturschalen eingesetzt wurden und daß das Wasser nach etwa einer Stunde erneuert wurde, wobei die Polypen vorsichtig abgespült wurden. Bei regelmäßiger Fütterung vermehrten sich die Polypen sehr schnell, und aus dem Anfangsmaterial von etwa 30 Primärpolypen wurden inzwischen Tausende von Sekundärpolypen gezüchtet.

Einen großen Fortschritt bedeutet auch bei dieser Art die zweigliedrige Kultur mit dem Harpacticiden Tisbe holothuriae, der sich leicht in Massenkulturen zur Vermehrung bringen läßt. Dieser bodenbewohnende Copepode von geringer Größe frißt die Faeces der Polypen, weidet Bakterien und andere Mikroorganismen ab, hält somit die Kulturen sauber und dient gleichzeitig den Polypen zur Nahrung. Die Verwendung von Tisbe bringt einen weiteren Vorteil mit sich. Die aus den Eiersäckchen der Weibchen ausschlüpfenden Nauplien sind von sehr geringer Größe (etwa $0,08 \mathrm{~mm}$ ), so daß sie als erste Nahrung für die Primärpolypen von Tripedalia geeignet sind. Das zeigte sich, als es im Frühjahr 1974 erstmals gelang, aus den Geschlechtsprodukten reifer Medusen Planulae und Primärpolypen der $F_{1}$-Generation zu erhalten, worauf bereits hingewiesen wurde. Die Fütterung mit Tisbe-Nauplien reichte aus, einen großen Teil über das kritische Anfangsstadium hinweg und zum weiteren Wachstum zu bringen. Die anfangs für unerläßlich gehaltene individuelle Fütterung war damit überflüssig geworden.

Auch die Medusen lassen sich im Laboratorium ohne allzu große Schwierigkeiten bis zur vollen Größe und Geschlechtsreife heranziehen. Sie wurden in Bechergläsern von 0,6 oder 1,01 Inhalt in stehendem Wasser bei täglicher Fütterung mit reichlich Tisbe, bei täglichem Wasserwechsel und in einer Kulturtemperatur von $25^{\circ}$ bis $27^{\circ} \mathrm{C}$ innerhalb von 10 bis 12 Wochen geschlechtsreif. Nach allem hat sich Tripedalia als günstiges Objekt für die Laboratoriumskultur erwiesen.

\section{BEFUNDE}

\section{Die Entwicklung der Planula zum Primärpolypen}

Die Medusen von Tripedalia cystopbora sind wie alle Cubomedusen getrenntgeschlechtig. Wie erst kürzlich entdeckt worden ist (WERNER, 1973a), lassen sich die Geschlechter durch die unterschiedliche Farbe und Struktur der Gonaden leicht unterscheiden. Ferner überträgt das Männchen in einem interessanten, für Medusen bisher unbekannten Paarungsspiel die zu Spermatozeugmen eines einfachen Typs vereinigten Spermatozoen in kugeligen Spermatophoren direkt auf das Weibchen. Die aus den reifen Gonaden in die Gastraltaschen ausgestoßenen Eier werden daher an Ort und Stelle besamt und entwickeln sich zu Planulae, ehe sie ausgestoßen werden und die 
kurze planktische Phase beginnen. Sie dauert nur 2-3 Tage, wie schon Conant (1898) beobachtet hat, der als erster die Larviparie einer Cubomeduse beschrieben hat (vgl. p. 463). Die Planulae haben eine rundliche bis stumpfovoide Form und eine schwach bräunliche Färbung. Thre Größe (maximaler Durchmesser) beträgt $0,13 \mathrm{~mm}$. Die Untersuchung eines Lebendquetschpräparates ergab, daß sie funk tionsfähige Nesselkapseln

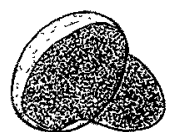

a
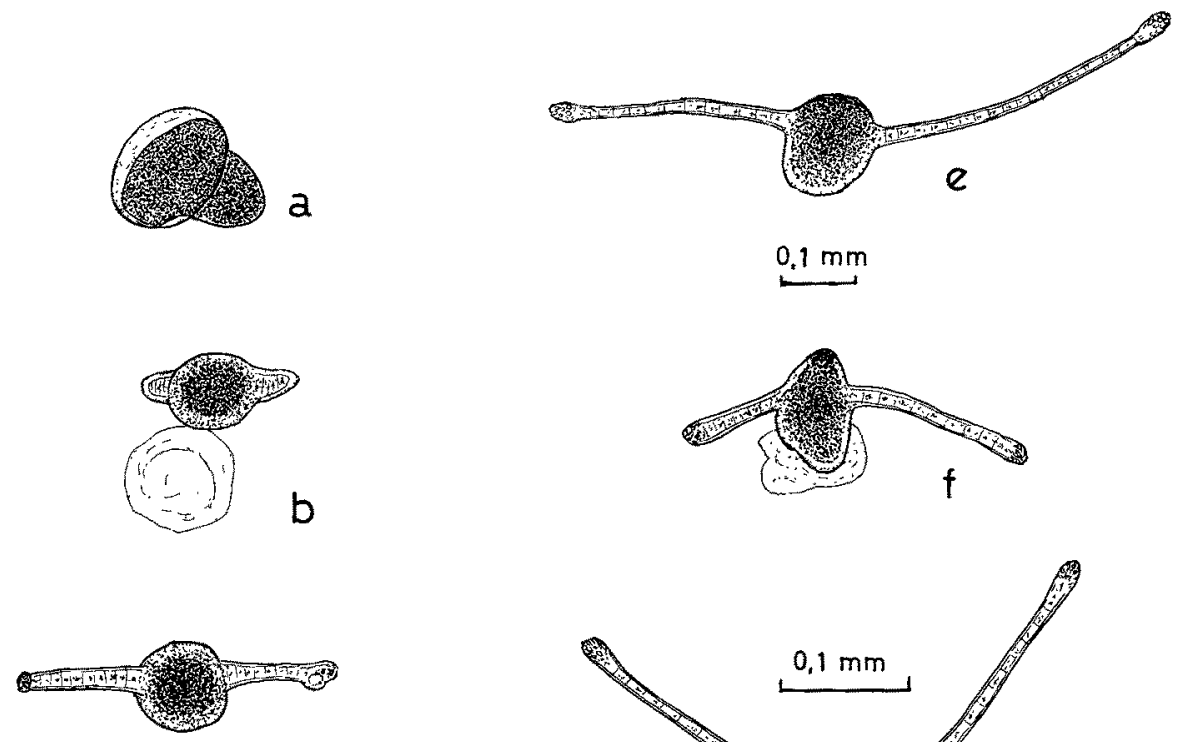

$\underline{0.1 \mathrm{~mm}}$

C
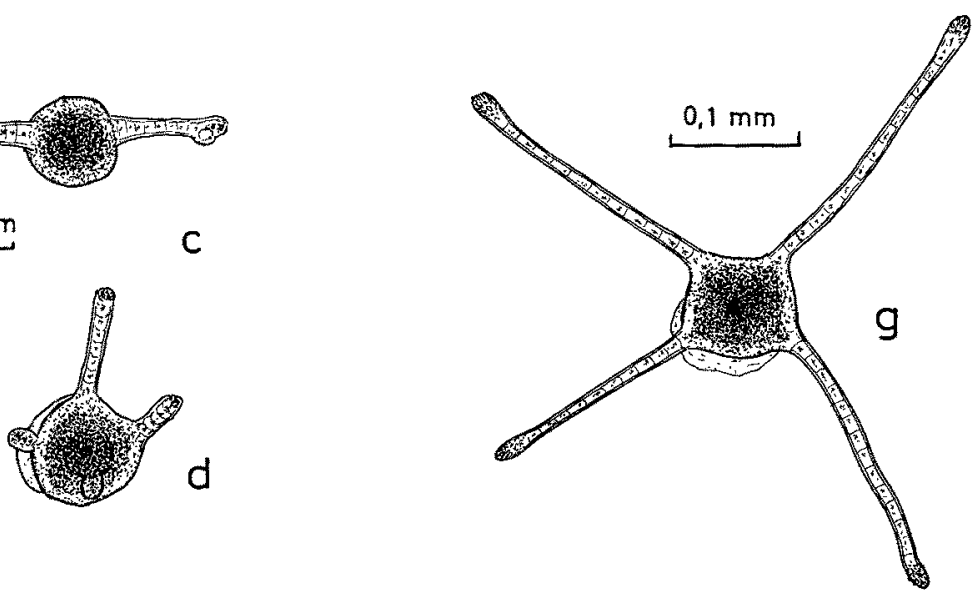

Abb. 2 a-g: Tripedalia cystophora, Entwicklung der angehefteten Planula zum jungen Primärpolypen. $a, b, c, d, g$ Aufsicht, $e$, f Seitenansicht. a zeigt das seitliche Ausschlüpfen des anfangs ungegliederten Keims aus der Planulahülle. Die Keime in $d, f, g$ sind nach oben durchgebrochen und behalten die Planulahülle als primären Peridermbecher. (Zeichnung: F. K. HEcKMANN nach Vorlagen des Autors)

vom Typ der mikrobasischen heterotrichen Eurytelen besitzen, die in zwei Formen und Größenklassen ausgebildet sind (Tab. 2). Der Zellinhalt ist relativ grobkörnig und enthält wenige gelbbraune Pigmentgranula, die der Planula die erwähnte Färbung verleihen.

Bei der Anheftung am Substrat, in den Kulturen auf dem Boden der Glasschalen, umgeben sich die Planulae mit einer feinen strukturlosen Peridermmembran, die von 
den Ektodermzellen ausgeschieden wird. Nach einer kurzen Ruheperiode von 2-3 Tagen, die offenbar der Vorbereitung für die weitere Differenzierung dient, durchbricht der zunächst noch ungegliederte Keim die Hülle und formt sich zum Primärpolypen um (Abb. 2, 3). Bei diesem entwickeln sich gleichzeitig meist zwei, kurz darauf über Kreuz 4 Tentakel; zuweilen werden auch sofort 3 Tentakel ausgebildet. Häufig

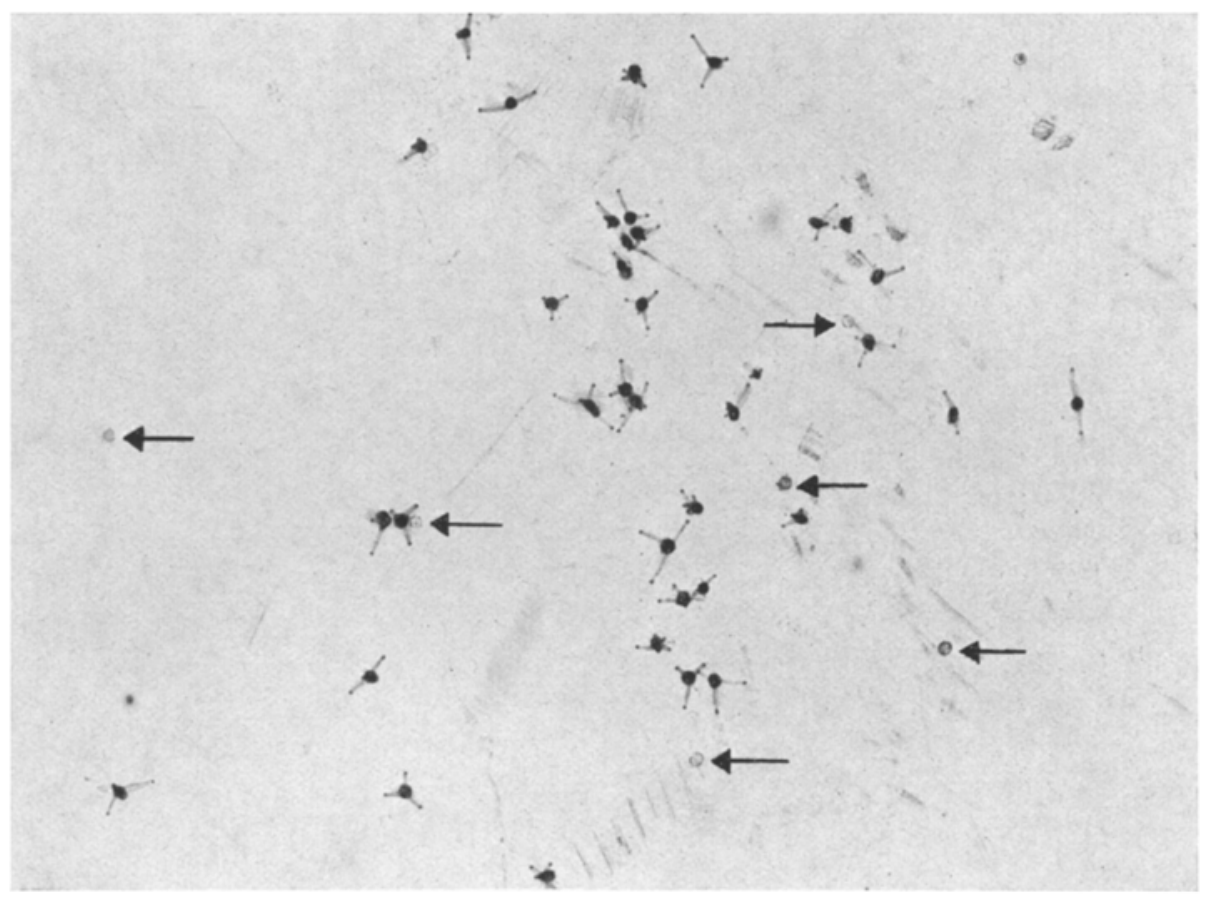

Abb. 3: Tripedalia cystopbora, Photo junger, 9 Tage alter Primärpolypen der F1-Generation. Die Pfeile deuten auf leere Planulahüllen hin, aus denen die Keime ausgeschlüpft sind

schlüpft der Embryo aus der Planulahülle vollständig aus, um sich dicht neben ihr oder in einiger Entfernung mit dem aboralen Pol erneut anzuheften, der sich zur basalen Haftscheibe entwickelt (Abb. 2b, 3). Das ist offenbar dann der Fall, wenn der Schlüpfspalt seitlich liegt. In anderen Fällen bricht der Keim nach oben durch und bleibt dann in der primären Hülle angeheftet, die zum basalen Peridermbecher wird. Im ersteren Fall wird dieser von den Epidermiszellen des Basalteils neu ausgeschieden.

Auf diesem Stadium mit 3-4, maximal 5 Tentakeln verharren die Primärpolypen etwa 1 bis 3 Wochen, ehe sie mit der Nahrungsaufnahme beginnen (p. 467). Die Größe ist von der der Planula kaum verschieden und beträgt 0,1-0,13 mm (Höhe = Durchmesser). Die Form ist variabel, halbkugelig oder stumpfkegelig. Der Mundkegel ist über dem Tentakelkranz bereits erkennbar. Körper und Mundkegel sind auch beim jungen Primärpolypen schon recht dehnungsfähig, wie sich bei der ersten Nahrungsaufnahme erkennen läßt, ein Merkmal, das wie die Variabilität der Körperform beim erwachsenen Polypen noch erheblich stärker ausgeprägt ist. 
Das weitere Wachstum vollzieht sich stetig, bis der Polyp nach etwa 5-6 Wochen eine Körperlänge von $0,5 \mathrm{~mm}$ (Höhe) hat und 4-7 Tentakel besitzt. Er erreicht dann die Phase der asexuellen Vermehrung durch seitliche Knospenbildung. Während dieser Periode, die der Vergrößerung des Bestandes dient, wächst der Polyp weiter und erreicht mit einer Größe (Höhe) von durchschnittlich 1,0 $\mathrm{mm}$ und einer Tentakelzahl von meist 6-11 den erwachsenen Zustand vor der Metamorphose.

\section{Die Morphologie des Polypen}

Ein wesentliches Merkmal ist der solitäre Habitus, da weder bei Primär- noch bei den durch Knospung entstandenen Sekundärpolypen Anzeichen einer Verzweigung oder Stolonenbildung beobachtet wurden. Das gleiche gilt auch für den Polypen von Carybdea. Wie die Abbildungen 4, 6 und 9 erkennen lassen, kann beim Polypen von Tripedalia die Grundform des Körpers als stumpfkegelig bis flaschenförmig bezeichnet werden. Die untere Körperhälfte ist meist verbreitert, so daß der Körper seinen größten Durchmesser unterhalb des Tentakelansatzes erreicht. Die Tentakel sind in einem Kranz angeordnet (Abb. 5) und setzen am Körper einzeln, das heißt ohne basale Verbindung an, doch ist der Basalteil etwas verdickt. Oberhalb des Tentakelkranzes erhebt

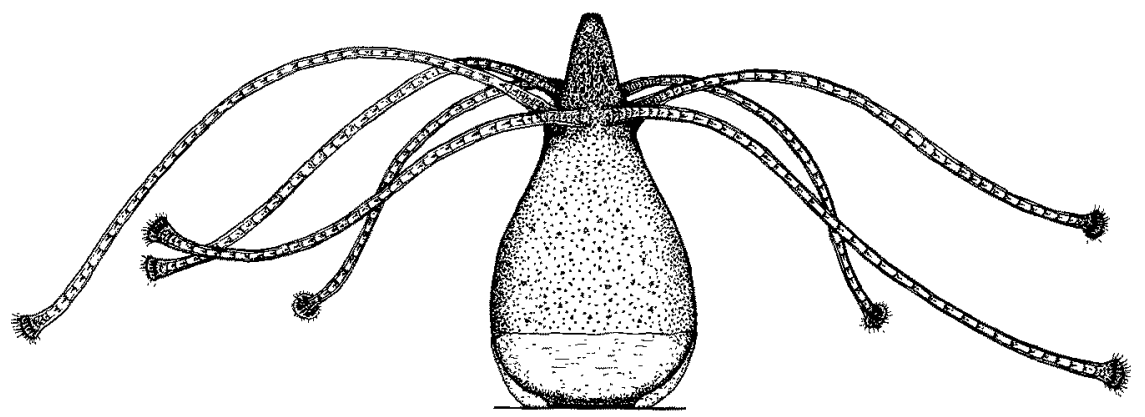

Abb. 4: Tripedalia cystophora, erwachsener Polyp, Seitenansicht. (Körperlänge 1,0 mm)

sich der sehr muskulöse Mundkegel oder die Proboscis, die im Ruhezustand eine Länge von etwa $1 / 5$ der Gesamtkörperlänge hat, also als recht groß bezeichnet werden muß. Bei der Nahrungsaufnahme zeigt sich, daß die Proboscis sehr dehnungs- und erweiterungsfähig ist, so daß sie im voll ausgestreckten Zustand einem Rüssel gleicht und auch die Funktion eines solchen hat. Eine entsprechend große Dehnungsfähigkeit besitzt der ganze Körper, so daß der Polyp eine Beute verschlingen kann, die den vorher im Ruhezustand befindlichen Körper an Größe übertrifft.

Das ist deswegen möglich, weil der größte Teil des Körpers nackt ist; nur die Basis ist von einem feinen strukturlosen Peridermbecher umgeben, der von den Epidermiszellen des Basalteils ausgeschieden wird. Durch seine zarte Beschaffenheit ist der Peridermbecher meist nur schwer zu erkennen; er tritt nur dann deutlicher in Erscheinung, wenn er mit Mikroorganismen oder Nahrungsresten bedeckt ist. Außerdem 
ist er besonders deutlich auszumachen, wenn der Polyp sich in die Kriechform zurückverwandelt, sich vom Substrat ablöst und aus der Hülle schlüpft (p. 482) oder wenn die Jungmeduse nach beendeter Metamorphose davonschwimmt, so daß der leere Peridermbecher zurückbleibt (p. 485). Die Unterseite des verschmälerten Basalteils ist als Haftscheibe ausgebildet. Erwähnenswert ist, daß die Anheftung nicht so intensiv ist, daß der Polyp mitsamt seinem Peridermbecher nicht durch einen kräftigen Pipettenstrahl abgespült werden könnte.

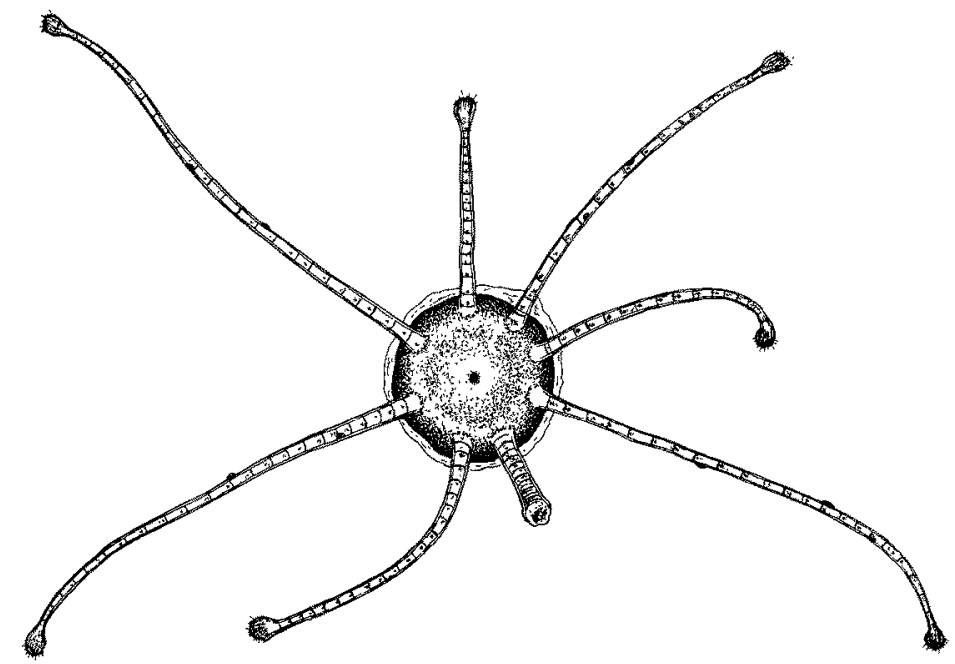

Abb. 5: Tripedalia cystophora, erwachsener Polyp, Aufsicht. (Zeichnung: F, K. Heckmann)

Der Weichkörper hat eine grauweiße bis gelbliche Farbe. Bei ausschließlicher Ernährung mit Artemia-Nauplien nimmt er eine rötliche Färbung an. Auf die Variabilität der Körperform wurde bereits hingewiesen; sie hängt vom Alter, von der Größe und vom jeweiligen Aktivitätszustand $a b$, der besonders mit der Ernährung korreliert ist. Gut ernährte Polypen haben im Ruhezustand, das heißt während einer mehrtägigen Fütterungspause, die schon erwähnte gedrungene Flaschenform (Abb. 4, 6, 9), während Hungertiere eine wesentlich schlankere Form haben. Häufig wird bei Ruhepolypen auch eine rundliche oder flache Körperform angetroffen, bei der der Querdurchmesser größer als die Höhe sein kann. Entsprechende Formänderungen zeigt auch der Mundkonus, der eine langgestreckte, breitniedrige oder rundliche Form annehmen kann. In den Abbildungen 7 und 8 ist die Variabilität der Körperform nach Lebendskizzen zahlreicher Polypen demonstriert. Dazu ist zu bemerken, daß die Umrißskizzen nach Polypen angefertigt wurden, die sich im Ruhezustand befanden, so daß sie nicht vorübergehende Formänderungen widerspiegeln, wie sie in Aktivitätszustand die Regel sind. Häufige und somit charakteristische Körperformen jüngerer und älterer Polypen sind in Abbildung 9 wiedergegeben.

Die Variabilität der Form betrifft vor allem den Basalteil, der vom Peridermbecher umgeben ist. Bei jüngeren Polypen, die sich an sauberem Substrat angeheftet haben, ist der Basalteil dicht oberhalb der schmäleren Haftscheibe im Verhältnis zur 


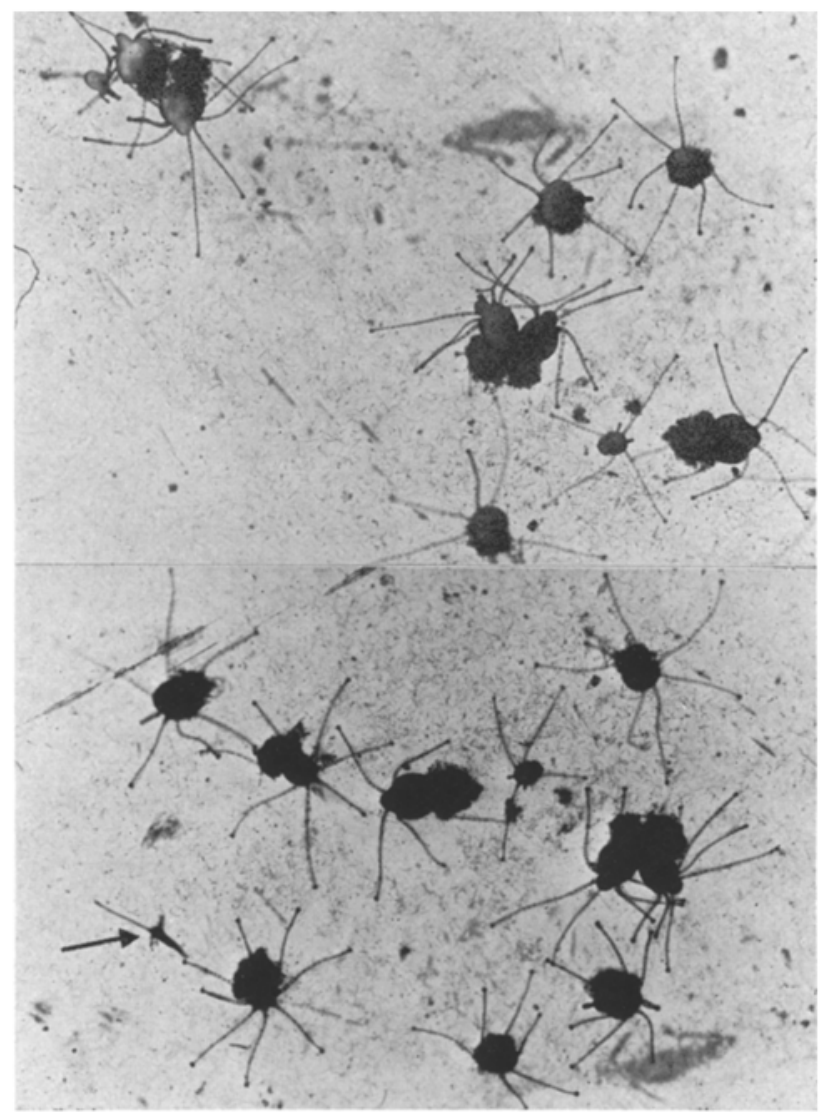

Abb. 6: Tripedalia cystophora, Photo erwachsener Polypen in Auf- und Seitenansicht. Der Pfeil deutet auf einen eben abgelösten Sekundärpolypen in der Kriechphase hin

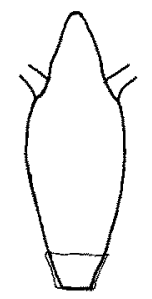

a

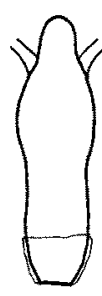

b

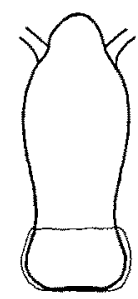

C

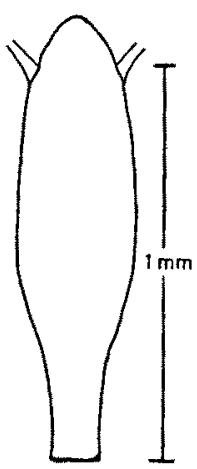

e

Abb. 7 a-e: Tripedalia cystophora, Habitusskizzen lebender Polypen in gestrecktem Zustand, Seitenansicht. Maßstabsgerechte Freihandzeichnungen verschiedener Tiere. Der basale Peridermbecher fehlt bei den Exemplaren d und e 

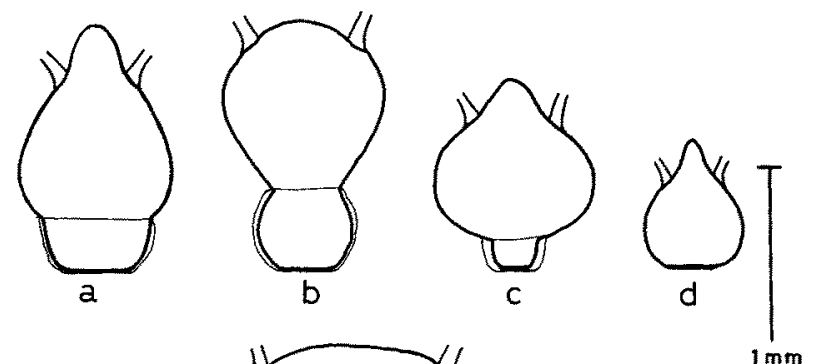

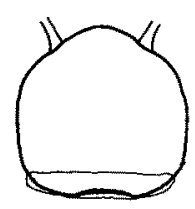

e
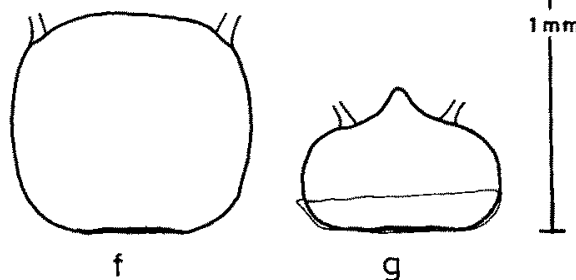

9

Abb. 8 a-g; Tripedalia cystophora, Habitusskizzen lebender Polypen in mehr oder weniger kontrahiertem $\mathrm{Zustand}$, Seitenansicht. $\mathrm{Zu}$ beachten ist in $\mathrm{a}-\mathrm{c}$ die Stielform des Basalteils, die durch die engen Peridermbecher bedingt ist

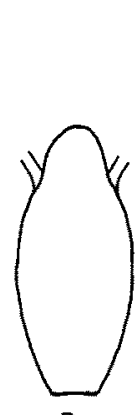

a
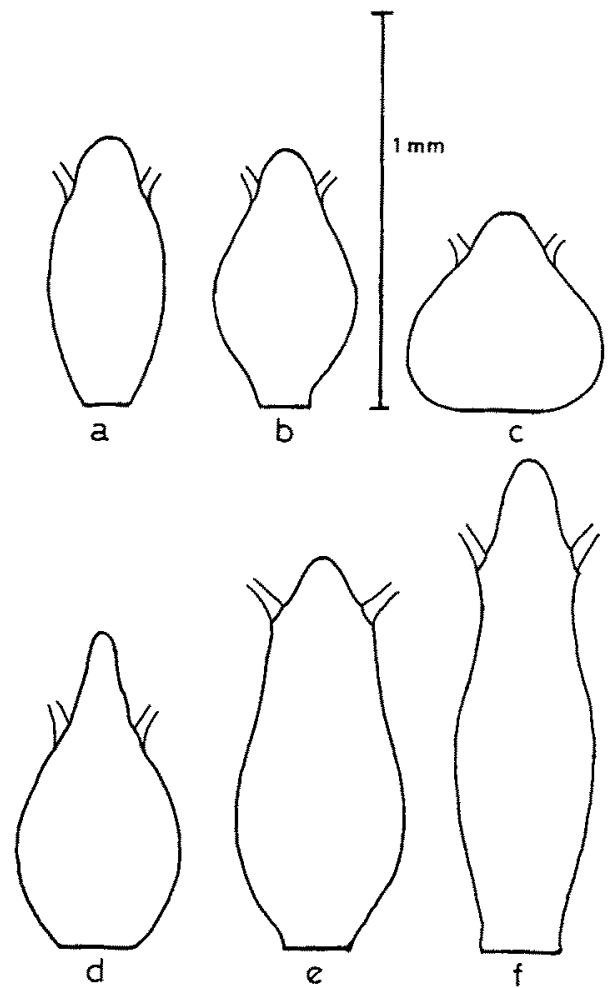

Abb. 9 a-f: Tripedalia cystophora, Habitusskizzen lebender Polypen zur Demonstration der häufigsten Körperformen. Basale Peridermbecher nicht gezeichnet 
Körperlänge relativ breit. Bei älteren Tieren läßt sich beobachten, daß die Basis schlanker ist als der mittlere Körperteil, so daß sie stielförmig ausgebildet ist. Nach den vergleichenden Beobachtungen hat es den Anschein, daß in solchen Fällen die schlankere Stielform des Basalteils sekundärer Natur ist. Sie wird dadurch verursadht, daß die Außenseite des Peridermbechers mit ausgeschiedenen unverdaulichen Nahrungsresten (z. B. Chitinteilen der gefressenen Nahrungstiere) oder mit Mikroorganismen dicht besetzt ist, so daß er seine natürliche Elastizität verliert. Beim Wachstum des Polypen

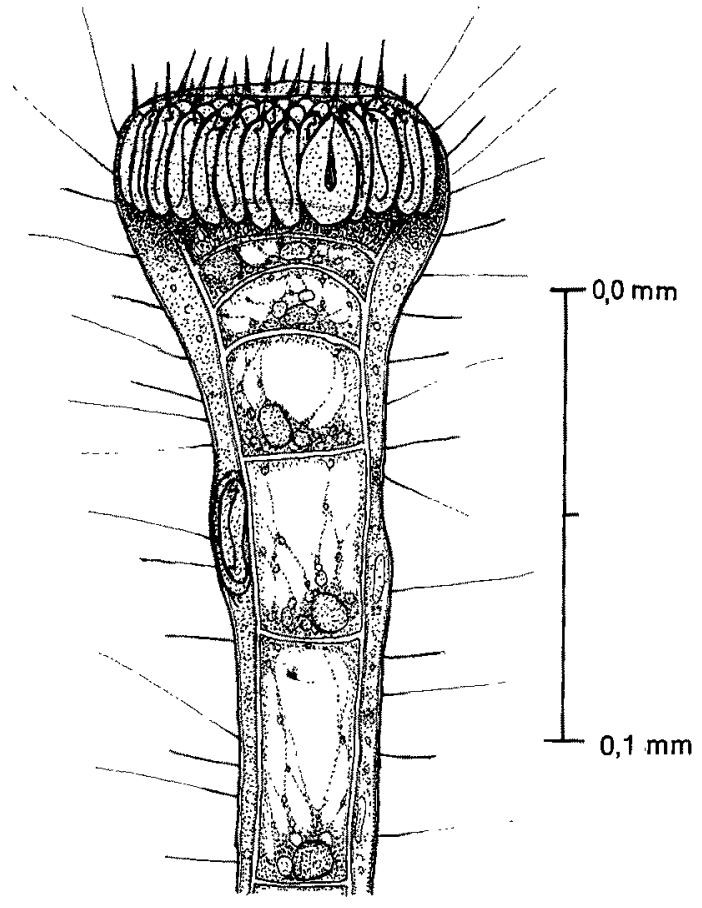

Abb. 10: Tripedalia cystophora, Endteil eines Tentakels. Beachte auf der linken Seite die in Wanderung begriffene Nesselzelle sowie die beiden Typen von Nesselkapseln im Endkolben. Vorderfront mit Cnidocils, Seiten mit kürzeren, kräftigeren und längeren, zarten Sinnesborsten besetzt

muß sein Basalteil dann notwendig die Stielform annehmen. Löst man einen solchen Polypen aus seinem Peridermbecher heraus oder verläßt er ihn aktiv (p. 482), so nimmt der Körper nach der Anheftung wieder die breitere Form des Basalteils an. Die gleiche Erscheinung läßt sich bei Polypen beobachten, die nach einer inaktiven Phase aus der Cystenhülle ausschlüpfen (s. p. 482, Abb. 17). Die eingehendere histologische Untersuchung muß zeigen, ob sich der Basalteil in Strukturmerkmalen von den höheren Körperpartien unterscheidet.

Variabel sind auch die Zahl, Länge und Haltung der Tentakel. Wie Zählungen ergeben haben, schwankt die Zahl der Tentakel bei erwachsenen Polypen durchschnitt- 
lich zwischen 6 und 11; die Maximalzahl war 12. Im vollausgestreckten Zustand haben die Tentakel das Mehrfache der Körperlänge, was vor allem bei Hungertieren beobachtet werden kann. Nach der Nahrungsaufnahme sind die Tentakel meist mehr oder weniger kontrahiert. Ihre Kontraktionsfähigkeit ist so erheblich, daß sie vollständig in den Körper eingezogen werden können. Sie ragen dann über die Körperoberfläche überhaupt nicht mehr heraus und sind nur noch als rundliche Flecken erkennbar. Eine derart starke, reversible Kontraktilität der Tentakel ist meines Wissens noch bei keinem anderen Polypen beobachtet worden.

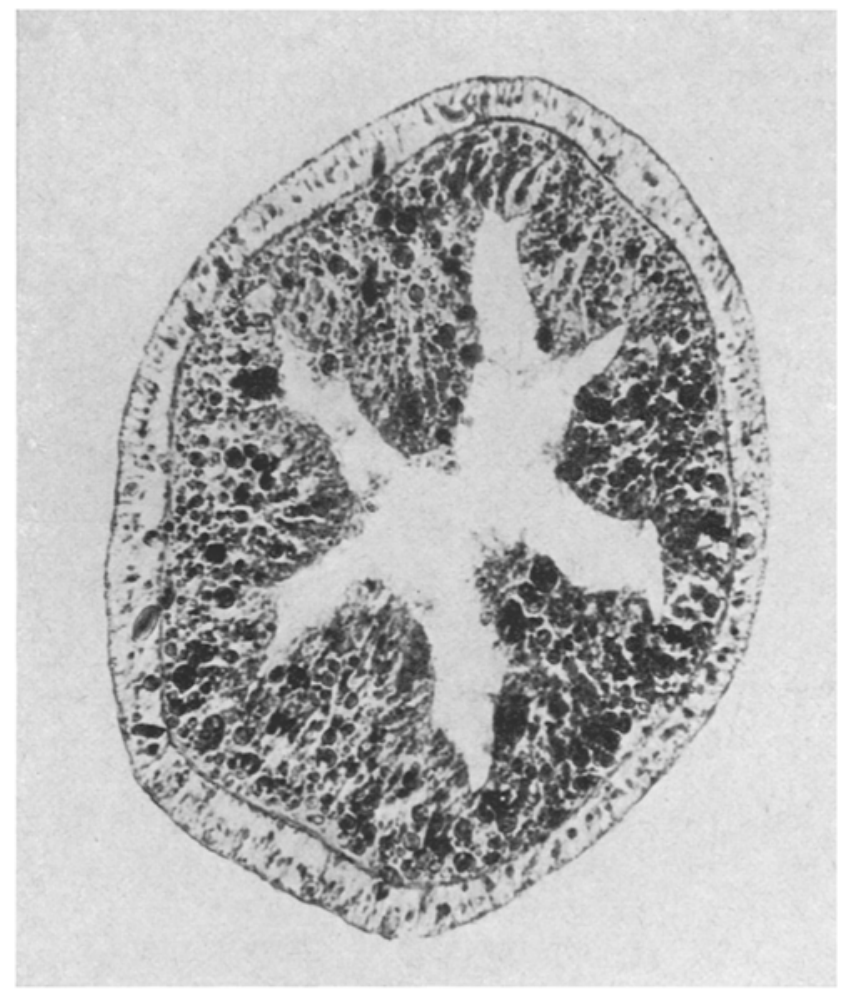

Abb. 11: Tripedalia cystophora, Querschnitt durch den Körper eines Polypen im Ruhezustand

Hinsichtlich ihrer Haltung ist zu bemerken, daß die Tentakel unregelmäßig nach oben oder nach den Seiten ausgestreckt sind. Nicht selten sind die Tentakelenden dem Boden genähert oder liegen ihm auf. Das läßt darauf schließen, daß bodenbewohnende Evertebraten entsprechender Größe, etwa Nematoden oder Copepoden, zu den natürlichen Nahrungstieren gehören. Die soliden Tentakel des Polypen sind capitat, das heißt sie tragen Nesselzellen nur im Endknopf (Abb. 10). Allerdings werden nicht selten auch Nesselzellen zwischen der Basis und dem Endteil der Tentakel angetroffen; sie sind auf der Wanderung von der Bildungszone, die in der Körperoberfläche unterhalb des Tentakelansatzes liegt, zum Verbrauchsort begriffen. Eigenartig ist die An- 
ordnung der Nesselkapseln, da sie nicht an der Oberfläche des keulenförmig verdickten Endteils liegen, sondern in einer zentralen Grube eingesenkt sind. Daher besteht ein grundsätzlicher Unterschied zu den capitaten Tentakeln eines Hydroidpolypen, bei denen die Nesselzellen in die ektodermale Oberfläche der Peripherie des keulenförmigen oder kugeligen Endknopfes eingefügt sind, so daß dieser eine stachelige Oberfläche hat.

$\mathrm{Zu}$ erwähnen ist ferner noch, daß die Epidermis des Polypen von Tripedalia $\mathrm{n}$ i c h t mit schlagenden Geißeln besetzt ist, so daß auf der Körperoberfläche keine Geißelströme existieren. Dieses Merkmal ist indes offenbar sekundärer Natur, da die vergleichende Untersuchung gezeigt hat, daß der Polyp von Carybdea über lebhaft schlagende Geißeln der Körperepidermis verfügt. Hierbei handelt es sich um eines der wenigen Merkmale, das ein Cubopolyp mit dem Scyphopolypen gemeinsam hat.

Auf einen entscheidenden morphologischen und anatomischen Unterschied wurde bereits in der Einleitung hingewiesen, der mit der Radialsymmetrie des Körpers gegeben ist; sie wird durch die Abbildungen hinreichend illustriert. Thr entspricht wie beim Hydroidpolypen der Mangel der inneren Gliederung, so daß der Polyp von Tripedalia einen einfachen sackförmigen Körperbau besitzt. Die Körperwand besteht überall nur aus den beiden Schichten des Ektoderm und Entoderm mit der dazwischenliegenden dünnen Mesogloea (Mesolamelle). Wie schon erwähnt, fehlen die für den Scyphopolypen typischen tetrameren Strukturen, nämlich Gastralsepten mit Septalmuskeln und Gastraltaschen. Bei den im Ruhezustand befindlichen größeren Polypen kann das Entoderm allerdings gefaltet sein (Abb. 11); es handelt sich aber nicht um Septen, sondern eben nur um Längsfalten, die in wechselnder Zahl auftreten und mit der starken Kontraktions- bzw. Expansionsfähigkeit des Körpers vor oder nach der Nahrungsaufnahme zu erklären sind. Wenn der Gastralraum mit Nahrung gefüllt ist, verschwinden die Falten des Entoderm, das dann im ganzen Umkreis des Körpers eine gleichmäßig dünne Wandstärke aufweist. Ahnliche Erscheinungen sind bekanntlich auch bei Hydroidpolypen anzutreffen.

\section{Die asexuelle Vermehrung durch Polypenknospung}

Etwa 5 Wochen nach der Anheftung der Planula und ihrer Umwandlung in den Primärpolypen ist bei diesem ein Zustand der Differenzierung erreicht, der durch die asexuelle Vermehrung gekennzeichnet ist. Sie erfolgt durch die Bildung von Polypenknospen, die seitlich an der Körperwand erzeugt werden und sich einzeln ablösen (Abb. 12, 14). Die Knospungszone liegt in der unteren Körperhälfte, meist etwas unterhalb des oberen Randes des Peridermbechers. Wie beim Suißwasserpolypen Hydra wölbt sich die Körperwand vor und formt sich zu einem kleinen Polypen mit Mund und 2 bis 3 Tentakeln um, der sich anschließend ablöst und davonkriecht (Abb. 13, 6). Die Dauer des Knospungsvorganges von der beginnenden Vorwölbung bis zur Ablösung des Sekundärpolypen beträgt bei $22^{\circ} \mathrm{C} 4$ bis 5 Tage und ist bei höheren Temperaturen etwas geringer. Der bei der Abschnürung zunächst rundliche oder ovoide Sekundärpolyp ist nackt; er streckt sich und schlïpt aus dem Peridermbecher des Erzeugerpolypen aus, um sich nach einer kürzeren oder längeren Periode des 
Umherkriechens an einer geeigneten Stelle anzuheften und sich zum sessilen Polypen umzuformen. Dabei umgibt sich der Basalteil des Körpers mit einem zarten Peridermbecher, so daß sich der entstandene Sekundärpolyp nur durch die geringere Größe und Tentakelzahl vom Erzeugerpolypen unterscheidet.

Je nach Alter, Größe und Ennährungszustand des Primärpolypen haben die abgelösten Sekundärpolypen eine unterschiedliche Größe; als Durchschnittswert kann eine Körperlänge von 0,3 bis $0,4 \mathrm{~mm}$ nach der soeben erfolgten Anheftung angegeben werden. Ein Sekundärpolyp ist also von Anfang an erheblich größer als der aus der Planula entstandene junge Primärpolyp und ist daher auch sofort in der Lage, einen Artemia-Nauplius zu erbeuten und ganz oder teilweise zu verschlingen. Die Aufzucht der Sekundärpolypen ist damit problemlos.
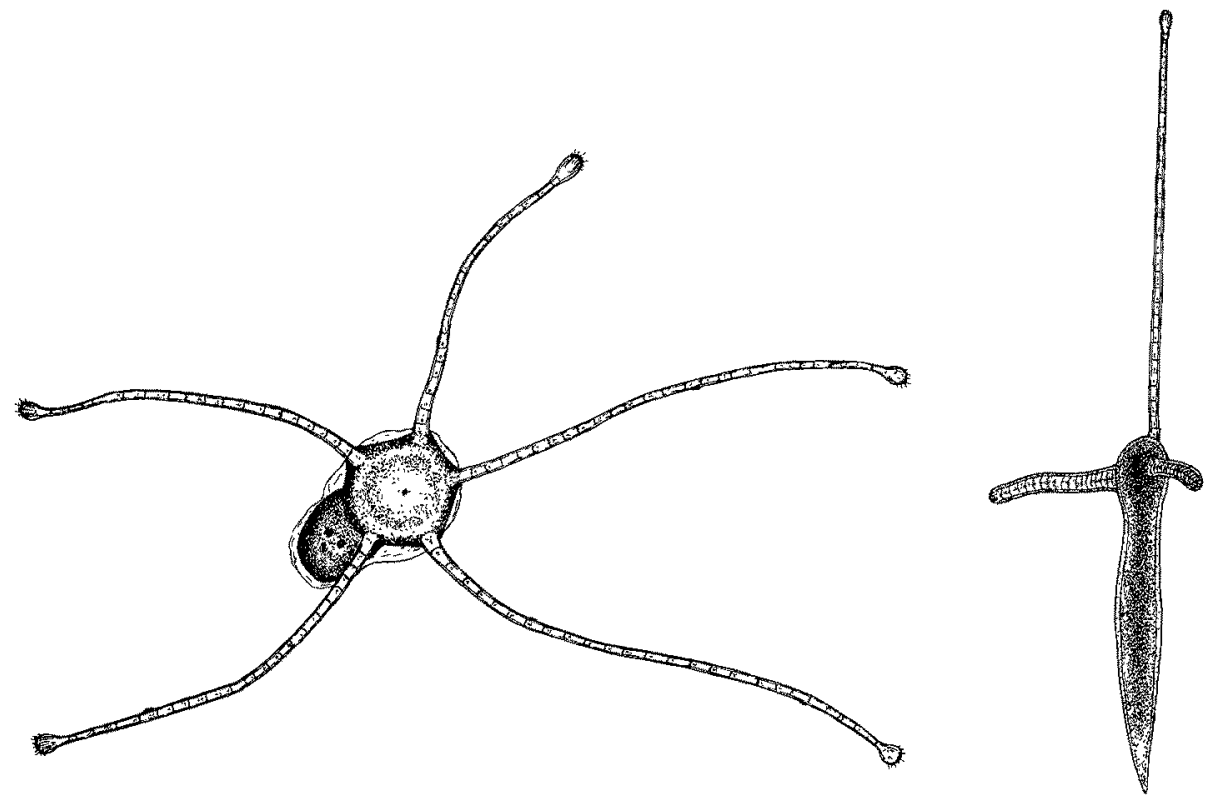

Abb. 12: Tripedalia cystophora, junger Polyp in Knospenbildung, Aufsicht. (Zeichnung: F. K. HeCKMANN)

Abb. 13: Tripedalia cystophora, Sekundärpolyp in der Kriechphase nach der Ablösung vom Erzeugerpolypen. Gesamtlänge 1,6 mm. (Zeichnung: F. K. HeCKMANN)

Bemerkenswert ist der Habitus des abgelösten Sekundärpolypen während der anschließenden Kriechphase (Abb. 13), in der der Kopfteil mit den Tentakeln stets vorangetragen wird. Der Körper ist außerordentlich stark gestreckt, verschmälert und abgeflacht, wobei der aborale Pol zu einer Spitze ausgezogen ist. Typisch ist ferner, daß einer der Tentakel bis zur Grenze der Dehnungsfähigkeit gestreckt ist, so daß er wie eine Suchantenne vorangetragen wird und offenbar auch als Tastorgan dient. Durch die starke Streckung wird der Körper des Sekundärpolypen während der Kriechphase erheblich verlängert. Die durchschnittliche Länge (20 Messungen) beträgt 1,2 mm, wovon $0,6 \mathrm{~mm}$ auf den Körper und $0,6 \mathrm{~mm}$ auf den gestreckten Tentakel entfallen. 
Die Kriechgeschwindigkeit ist gering; es wurden Geschwindigkeiten von 0,072 bis $0,223 \mathrm{~mm}$ pro Minute gemessen, so daß pro Stunde ein Weg bis $\mathrm{zu} 13,4 \mathrm{~mm}$ zurückgelegt werden kann. Wie die Bewegung erfolgt, ist noch ungeklärt. Sie ist keinesfalls auf Geißeltätigkeit zurückzuführen, da die Körperoberfläche des Kriechpolypen ebenso wie die des erwachsenen Polypen unbegeißelt ist. Die Fortbewegung des Körpers ist auch nicht mit rhythmischen Kontraktionen und Streckungen verbunden, wie sie für die Wanderfrusteln des Süßwasserpolypen Craspedacusta sowerbii und der marinen Form Gonionemus vertens (syn. G. murbachi) so charakteristisch sind (KuHL, 1947; WeRnER, 1950). Bei diesen Arten zeigt bekanntlich das Vorderende der kriechenden Frustel ein rhythmisches Vor- und Zurücksetzen, wie es in ähnlicher Form auch bei der auswachsenden Stolonenkappe koloniebildender Hydroidpolypen beobachtet wird (Wyttenbach, 1968). Vielleicht wird es möglich sein, die Art der Bewegung der Kriechpolypen von Tripedalia mit dem Hilfsmittel der Zeitrafferfilmaufnahme und Teilbildanalyse aufzuklären.

Die Dauer der Kriechphase ist variabel; meist beträgt sie 2-3 Tage. Offenbar dient der Kriechvorgang, durch den sich der Sekundär-vom Erzeugerpolypen entfernt, der Suche nach einem geeigneten Anheftungsplatz. Der eingeschlagene Weg hängt anscheinend vom Zufall ab; ebenso dürfte die Kriechrichtung zufälliger Natur sein. Im Endeffekt wird daher eine Kulturschale mehr oder weniger gleichmäßig dicht besiedelt. Oft wurde allerdings beobachtet, daß die Kriechpolypen sich an den Wänden der Kulturschalen nach oben, also in Richtung auf die Wasseroberfläche bewegten und sich

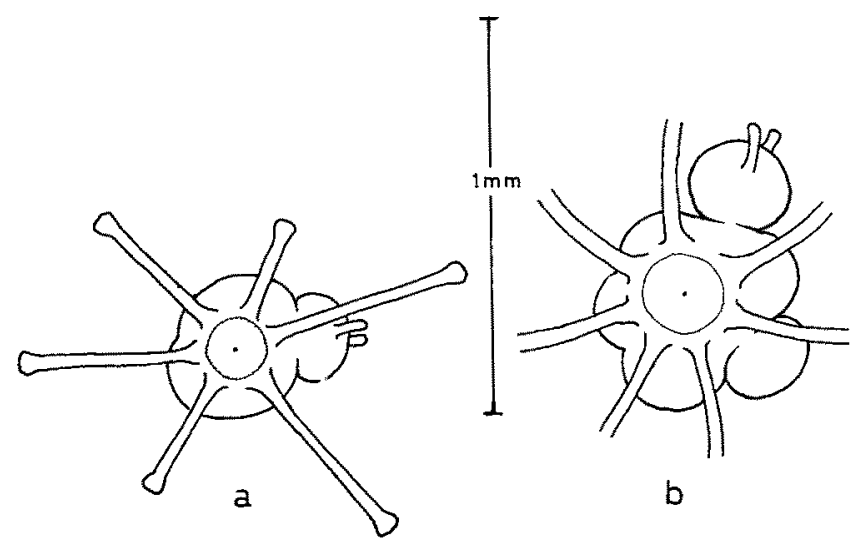

Abb. 14 a, b: Tripedalia cystophora. Habitusskizzen älterer Polypen in der Knospungsphase, Aufsicht. Beachte in $b$ die gleichzeitige Anlage von mehreren Knospen mit verschiedenem Differenzierungszustand

dicht unterhalb der Grenzlinie ansiedelten. $\mathrm{Ob}$ dabei ein physiologisch wirksamer Gradient, etwa die bessere $\mathrm{O}_{2}$-Versorgung in Oberflächennähe oder ob auch hier der Zufall eine Rolle spielt, weil die Wasseroberfläche der weiteren Wanderung eine Grenze setzt, läßt sich ohne entsprechende Versuche nicht entscheiden. Bei der Anheftung kontrahiert sich der Körper des Sekundärpolypen, das zugespitzte Hinterende verbreitert sich zur Haftscheibe und der Basalteil umgibt sich mit einem Periderm- 
becher. Wie der Primärpolyp wächst auch der junge Sekundärpolyp nach der Anheftung stetig weiter und geht im entsprechenden Differenzierungsstadium seinerseits zur Knospenbildung über.

Nach der Ablösung einer Knospe verharren die Polypen in einer Ruhephase von wenigen Tagen, während derer Reservestoffe für die Bildung der nächsten Knospe gespeichert werden. Bei jüngeren Polypen wird daher meist nur eine in Bildung begriffene Knospe beobachtet. Bei guter Ernährung und bei niederen Temperaturen kann der zeitliche Abstand der Bildung und Ablösung der Knospen verringert sein, so daß zwei oder mehrere Knospen gleichzeitig am Erzeugerpolypen vorhanden sind. Meist besteht aber ein mehr oder weniger deutlicher Differenzierungsunterschied, so daß sie sich nicht gleichzeitig, sondern nacheinander ablösen. In solchen Fällen weist der normalerweise im Querschnitt runde Körper in der Aufsicht durch die sich vorwölbenden Knospen Längsfalten auf. In extremer Weise ist das bei alten, reichlich ernährten Polypen der Fall, die durch niedrige Temperaturen verhindert werden, sich in Medusen umzuwandeln (Abb. 14b).

Durch die asexuelle Vermehrung vergrößert sich der Originalbestand an Polypen sehr schnell. Außerdem kann wie beim Süßwasserpolypen $H y d r a$ und bei der Verzweigung mariner koloniebildender Formen angenommen werden, daß die Knospung dazu dient, daß sich der Einzelpolyp der durch gute Ernährung gewonnenen überschüssigen Substanz wieder entledigt (vgl. SHOsTAK, 1974). Wie bereits kurz angedeutet, läßt sich die asexuelle Vermehrung des Polypen von Tripedalia in einfacher Weise

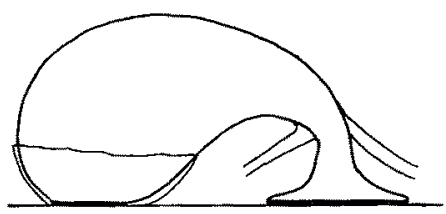

Abb. 15: Tripedalia cystopbora, Habitusskizze eines Polypen, der sidh bei der Nahrungssuche mit der weitgeöff neten Proboscis am Boden angesaugt hat. Seitenansicht

steuern, da die Metamorphose in die Meduse ein temperaturabhängiger Prozeß ist, der an Mindesttemperaturen von $23-24^{\circ} \mathrm{C}$ gebunden ist. Entsprechend verharrt der Polyp bei einer niederen Temperatur von $22^{\circ} \mathrm{C}$ ständig in der Phase der asexuellen Vermehrung durch Knospenbildung. Dieser Prozeß ist durch die Vergrößerung des Bestandes für die Art aus dem Grunde von besonderer Bedeutung, weil der Polyp solitär ist und weil seine Existenz mit der Umwandlung in die Meduse unwiderruflich beendet wird.

\section{Verhaltensformen des Polypen}

Wie bei allen festsitzenden Organismen und speziell bei den anderen sessilen Cnidariern sind die Verhaltensformen des Polypen von Tripedalia einfacher Natur und beziehen sich normalerweise, das heißt unter ausreichenden Lebensbedingungen, auf den Nahrungserwerb. Dieser ist überwiegend passiv; der Polyp ist also auf den Fang 
von Beutetieren angewiesen, die sich ihm zufällig nähern und zufällig die Endabschnitte seiner Tentakel berühren. Nach allen Beobachtungen wird die Beute nur von den Nesselkapseln der Tentakelenden festgehalten und getötet. Anschließend verkürzen sich die Tentakel; dabei ist auffällig, daß sich zuerst die Endabschnitte der Tentakel ruckartig kontrahieren, dann auch langsam ihre Basalteile. Auf diese Weise wird die Beute dem Körper genähert und kommt in den Bereich der dehnbaren rüsselförmigen Proboscis, die sich zu ihr aktiv hinstreckt und sie mit der erweiterten Mundöffnung verschlingt.

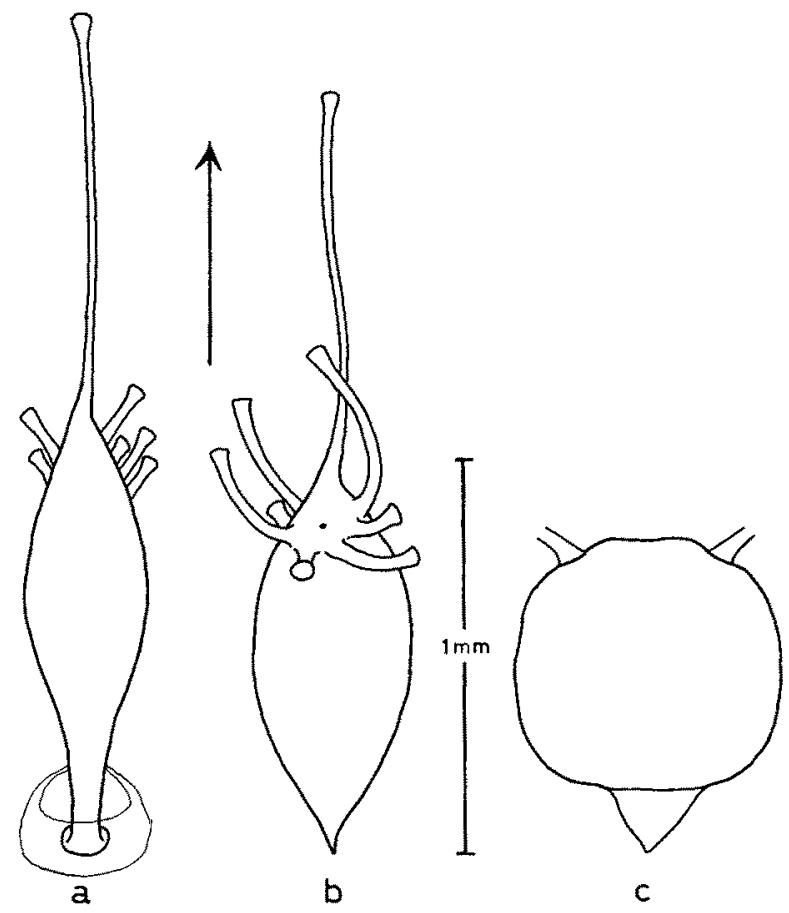

Abb. 16 a-c: Tripedalia cystopbora, erwachsene Polypen in der Kriechphase, a vollausgestreckter Polyp bei Beginn der Ablösung, Mund auf der Unterseite des Kopfteils, b freikriechender Polyp, Mund auf der Oberseite; der Pfeil zeigt die Kriechrichtung an; c Polyp, der nach Beendigung der Kriechphase im Begriff ist, sich wieder anzuheften, a-c verschiedene Tiere

Daneben besitzt der Polyp die ungewöhnliche Fähigkeit, die Bodenoberfläche in seiner Umgebung aktiv nach Nahrung abzusuchen. Der Körper streckt sich dabei in die Länge und biegt sich zum Boden hin, woran die Proboscis in besonderer Weise beteiligt ist. Es wurde beobachtet, daß sich die Mundöffnung stark verbreitert, so daß sich der Polyp mit der Proboscis wie mit einer Saugglocke an den Boden anpreßt (Abb. 15). Ob auf diese Weise auch Mikroorganismen dem Polypen zur Nahrung dienen können, bedarf noch der Untersuchung.

Außerdem läßt der Polyp in seinem Verhalten besondere Erscheinungen erkennen, die offenbar als Reaktionen auf veränderte Lebensbedingungen gedeutet werden müs- 
sen und ihm eine besondere Plastizität verleihen. Merkwürdigerweise ist der Polyp nämlich in der Lage, sich vom Boden vollständig abzulösen, aus dem Peridermbecher auszuschlüpfen und kriechend einen neuen Anheftungsort aufzusuchen. Er streckt sich dabei in die Länge und nimmt die gleiche Kriechform an (Abb. 16), die auch der junge, durch Knospung entstandene Sekundärpolyp in der Kriechphase aufweist (vgl. Abb. 13). Der kriechende erwachsene Polyp unterscheidet sich nur durch die Körpergröße und die Tentakelzahl von einem Jungpolypen in der Kriechphase. Es wurde eine Kriechgeschwindigkeit bis zu $12 \mathrm{~mm} / \mathrm{Std}$. gemessen. Nach Beendigung der Wanderperiode setzt sich der erwachsene Polyp mit dem Aboral- = Basalpol erneut fest und nimmt die normale Körperform wieder an. Auf die ökologische Bedeutung der Kriechfähigkeit des erwachsenen Polypen, die in ähnlicher Weise nur vom Süßwasserpolypen Hydra (wenn auch mit anderer Bewegungsweise) bekannt ist, wird später noch kurz eingegangen (p. 494).

Eine weitere bemerkenswerte Eigenschaft des Polypen von Tripedalia, die Ausdruck seiner Plastizität ist, besteht in seiner Fähigkeit, sich zu enzystieren. Er kontrahiert dabei im angehefteten Zustand seine Tentakel, kugelt sich ab und umgibt sich mit

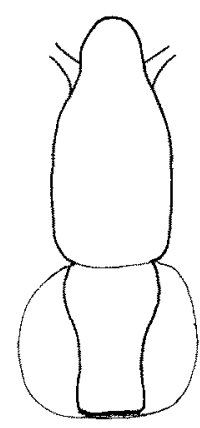

a

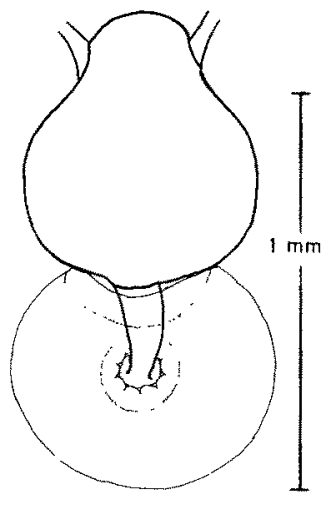

b

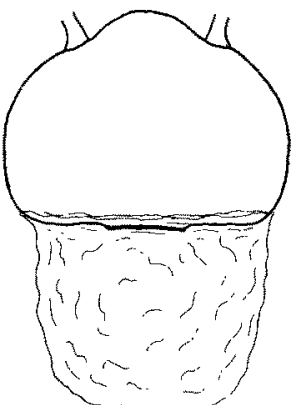

$\mathrm{C}$

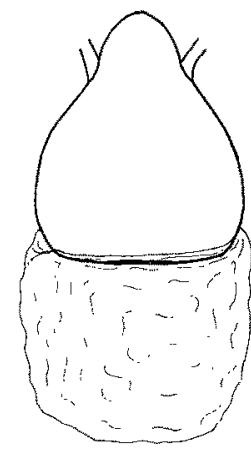

d

Abb. 17 a-d: Tripedalia cystophora, Habitusskizzen erwachsener Polypen beim Aussdlüpfen aus der Cystenhülle am Ende einer inaktiven Phase. b-d das gleiche Tier

einer allseitig geschlossenen zarten Peridermhülle, die von den Epidermiszellen ausgeschieden wird. In diesem inaktiven Zustand, in dem offenbar die Stoffwechselrate herabgesetzt ist, kann der Polyp Hungerperioden oder Zeiten allgemein ungünstiger Lebensbedingungen von längerer Dauer überstehen. Beim Eintritt günstigerer Bedingungen streckt sich der Polyp, durchbricht die Peridermhülle und setzt die Existenzform in der normalen Weise fort. Es wurde beobachtet, daß der Polyp vollständig aus der Cystenhülle ausschlüpfen und sich kriechend einen neuen Anheftungsort suchen kann (Abb. 17). Alle Tätigkeiten und Reaktionen des Polypen laufen wie bei den meisten Cnidarierpolypen in sehr langsamem Tempo ab. Gleichwohl lassen die Beobachtungen erkennen, daß er in seinem ganzen Verhaiten eine größere Aktivität und mehr Reaktionsmöglichkeiten besitzt, als sie von einem Scyphopolypen bekannt sind. Wie- 
weit indes die für den Polypen von Tripedalia beschriebenen Phänomene einer experimentellen Prüfung zugänglich und ob sie wie vermutet tatsächlich Reaktionen auf Umweltveränderungen sind, bedarf der genaueren Untersuchung.

\section{Die Metamorphose des Polypen in die Meduse}

Die Art der Entstehung der Cubomeduse ist in der Literatur mehrfach diskutiert worden, auch wenn reale Beobachtungen fehlten. Da nach den Befunden von Conant (1898) und OKADA (1927) an der Existenz der Polypengeneration mit Recht nicht gezweifelt wurde, nahm man allgemein an, daß die Meduse durch einen Knospungsvorgang gebildet würde. $\mathrm{Zu}$ dieser Auffassung hat vor allem eine Einzelbeobachtung von HAACKE (1887) beigetragen, der am Apikalpol einer Jungmeduse von Carybdea rastoni einen Stielkanal sah, wie er bei frisch abgelösten Hydroidmedusen in der apikalen Schirmgallerte nicht selten beobachtet wird, die ja ihre Entstehung einem Knospungsvorgang verdanken. Interessanterweise findet sich daneben aber auch die Vermutung, daß die Cubomeduse aus dem Polypen durch dessen vollständige Umwandlung entstehen könnte (KRUMBACH, 1924; p. 574). Zuletzt hat UCHIDA (1969; p. 248) das Problem der Ontogenie der Cubomeduse erörtert und 4 Möglichkeiten ihrer Bildungsweise angeführt: (a) die Knospung vom Polypen, (b) die Knospung von einem Stolo, (c) die direkte Metamorphose und (d) die Strobilation. Wenn sich UCHIDA auch schließlich für eine modifizierte Form des Bildungsmodus d, also für die Strobilation ausspricht, so bleibt doch höchst bemerkenswert, daß auch die direkte Metamorphose als Möglichkeit genannt wird, obwohl diese ungewöhnliche Form der Medusenbildung niemals bei irgendeiner Meduse der verschiedenen Gruppen beobachtet worden war.

So wurde die weitere Entwicklung des Polypen von Tripedalia mit begreiflicher Spannung verfolgt, und es zeigte sich schließlich, daß das Unerwartete zutraf: Der sessile Polyp wandelt sich in einer regelrechten Metamorphose direkt in die freischwimmende Meduse um. Ex unterscheidet sich damit vom Scyphopolypen, bei dem die Medusen durch Strobilation, das heißt terminale Querteilung, wie auch vom Hydroid-polypen, bei dem die Medusen durch seitliche Knospung als völlig neue Anlagen entstehen.

Nachdem das Grundphänomen erkannt war, ließ sich die Metamorphose des Polypen in verschiedene Phasen aufgliedern, die durch die äußerlich sichtbaren Formbildungsprozesse gekennzeichnet werden.

(a) Das erste Anzeichen der beginnenden Umwandlung besteht in einer Formänderung des Polypenkörpers, der wie erwähnt radiärsymmetrisch gebaut ist und über-all einen runden Querschnitt hat. Unter gleichzeitiger Verkürzung und Verbreiterung nimmt er durch 4 Längsfurchen der Körperwand eine in der Aufsicht bzw. im Querschnitt tetramere Form an (Abb. 18a). Diese Umformung in die tetramere Struktur bezieht auch die vorher regellos im Kreis verteilten Tentakel ein, die zu 4 Gruppen zusammengezogen werden. Es hängt dabei vom Zufall und von der Zahl der vorhandenen Tentakel $a b$, wie viele von ihnen dem jeweiligen Quadranten zugeordnet werden. Bei einer Gesamtzahl von 7 Tentakeln entfielen auf die 4 Quadranten und zwar in dieser Reihenfolge (Uhrzeigersinn) 3-1-2-1. Hatten die Polypen etwa 8 oder 9 Ten- 
takel, so enthielten die Gruppen 3-1-2-2 oder 3-2-2-2. Eine gewisse Regel war insofern erkennbar, als die sich gegenüberstehenden Gruppen entweder immer die größten oder kleinsten Zahlen aufwiesen, wie es die Abbildung 18a erkennen läßt. Der Mundkegel ist auf diesem Stadium erhalten und deutlich zu erkennen.
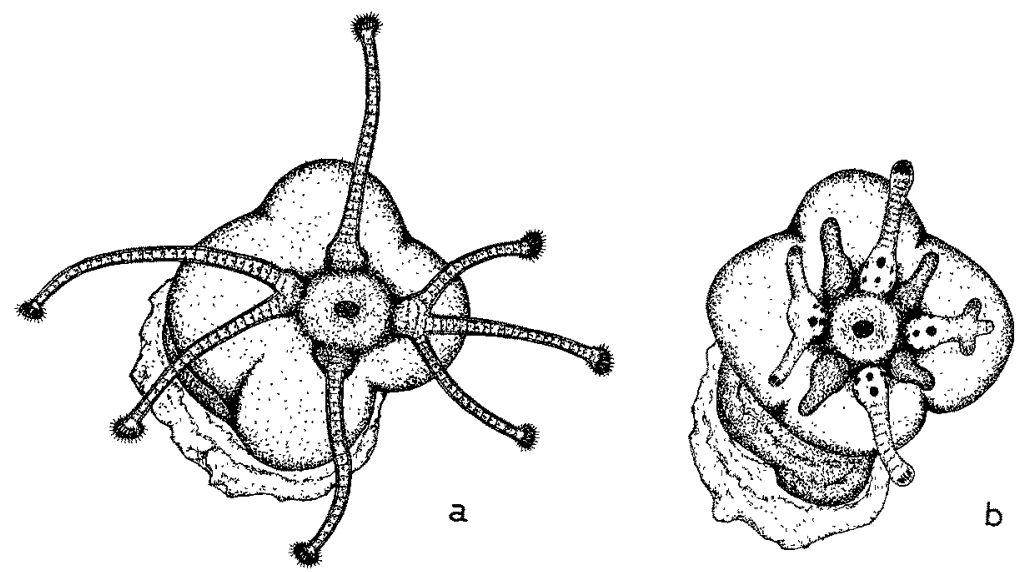

Abb, 18 a, b: Tripedalia cystophora, Anfangsstadien der Metamorphose des Polypen in die Meduse. Erläuterungen im Text. (Aus WerNER et al., 1971; Fig. 2, p. 583. Mit Erlaubnis des Herausgebers von Nature, London)
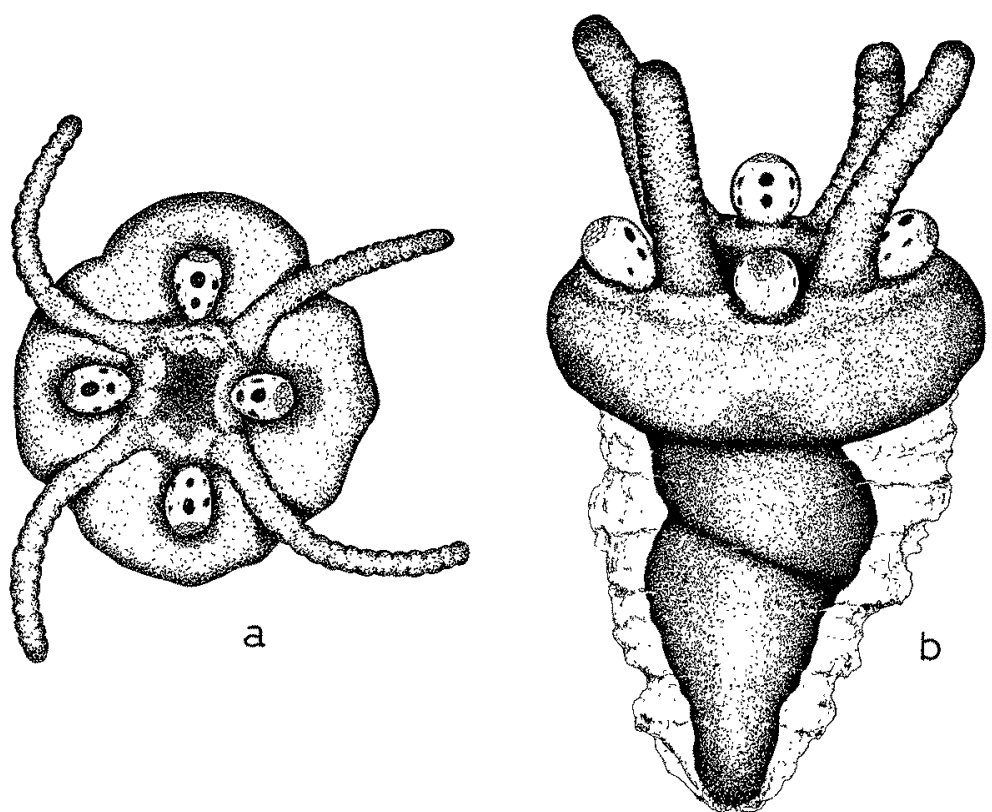

Abb. 19 a, b: Tripedalia cystophora, fortgeschrittene Stadien der Metamorphose; a Aufsicht auf den im Entstehen begriffenen Schirmrand, b Seitenansicht. Erläuterungen im Text. Größter Querdurchmesser $0,65 \mathrm{~mm}$. (Zeichnungen: F. K. HECKMANN) 
(b) Die Tetramerie des Körpers wird deutlicher, und die Tentakel rücken in den Gruppen so dicht zusammen, daß ihre Basen vereinigt werden (Abb. 18b, 2 Tage später). Würde man die radiärsymmetrische Anordnung der einzeln stehenden Tentakel beim Polypen nicht kennen, so müßte man auf Grund dieses Stadiums vermuten, daß sie an einer gemeinsamen Basis ansetzten. Gleichzeitig verkürzen sich die Tentakel, und es wird erkennbar, daß sich ihre Endabschnitte in Reduktion befinden. Mit der Bildung schwarzen Pigmentes an der Basis der Tentakelgruppen oder auch eines Einzeltentakels - wenn auf einen Quadranten nur 1 Tentakel entfiel -, deutet sich die Anlage der Sinnesorgane an, die aus der Basis der Tentakel hervorgehen.

(c) Die Reduktion der Endabschnitte der Tentakel schreitet fort. Zwischen ihren Basalteilen, die in der Umwandlung in die Sinnesorgane begriffen sind, entstehen 4 anfangs rundliche Ausstülpungen, bei denen es sich um die Anlagen der 4 Primärtentakel der in Bildung begriffenen Meduse handelt (Abb. 18b). Gleichzeitig beginnt im Umkreis des Mundkegels eine scheinbar ringförmige Einsenkung.

(d) Durch die völlige Reduktion des größten Teils der Tentakel erhalten die aus ihrer Basis gebildeten Sinnesorgane die definitive Form eines an einem kurzen Stiel befestigten Kolbens, der die charakteristischen Pigmentflecke, Linsen und den Kristallkörper enthält. Das Sinnesorgan (Rhopalium) der Cubomedusen erreicht bekanntlich die höchste, bei Medusen überhaupt bekannte Differenzierungsstufe. Gleichzeitig nehmen die Medusententakel an Länge zu (Abb. 19a, b). Die Einsenkung um den Mundkegel vertieft sich und hat häufig eine viereckige Form. Gleichzeitig verschwindet der Mundkegel mehr und mehr von der Oberfläche. Der vorher tetramere Körper wird von oben nach unten fortschreitend im Querschnitt rundlich. Die weiteren Umformungsprozesse, die auf den ganzen Körper übergreifen, spielen sich jetzt hauptsächlich im Inneren ab und führen zur Entstehung der Gastraltaschen, des Subumbrellarraumes und des Manubrium. Nur die Polypenbasis wird langsamer in den Prozeß einbezogen. Das läßt sich auch durch die Anderung der Färbung erkennen. Während der obere, in der Umformung begriffene Teil des Körpers eine charakteristische gelbbraune Färbung annimmt, bleibt der Basalteil durch die ursprünglich weißgelbe Farbe deutlich abgrenzbar.

(e) Die weitere Entwicklung ist mit der zunehmenden Größe, die mit der Verdünnung der Epithelien, der Bildung ds Schirms und der Vergrößerung des Subumbrellarraums zusammenhängt, sowie mit der Verkleinerung des basalen Restkörpers gekennzeichnet (Abb. 20), bis er schließlich vollständig in den Apikalpol der Meduse eingezogen wird. In dieser Endphase setzt die Kontraktionsfähigkeit des Schirms ein, und mit den für Cubomedusen so charakteristischen, schnell aufeinanderfolgenden Pulsationen schwimmt die Jungmeduse davon und läßt am Ort ihrer Entstehung nur den leeren Peridermbecher zurück.

Der Prozeß der Metamorphose des Polypen in die Meduse, wie er hier zunächst nur nach dem äußerlich sichtbaren Ablauf beschrieben wurde, setzt also am Oralpol ein und schreitet von hier in Richtung auf die Basis fort. Das gilt in gleicher Weise für die äußeren Umformungserscheinungen wie auch für die mit ihnen verbundenen Differenzierungsprozesse der inneren Strukturen. Obwohl die genauere anatomisch-histologische Analyse der Metamorphose noch aussteht und einer späteren Arbeit vorbehalten bleiben muß, ist nach den vorläufigen Untersuchungen doch schon erkennbar, daß die 
im Inneren ablaufenden Vorgänge einfachen Grundprinzipien folgen und daß sich zwei Hauptvorgänge unterscheiden lassen. (a) Die 4 geschlossenen Gastraltaschen der Meduse entstehen aus dem einheitlichen sackförmigen Körper des Polypen durch ver-

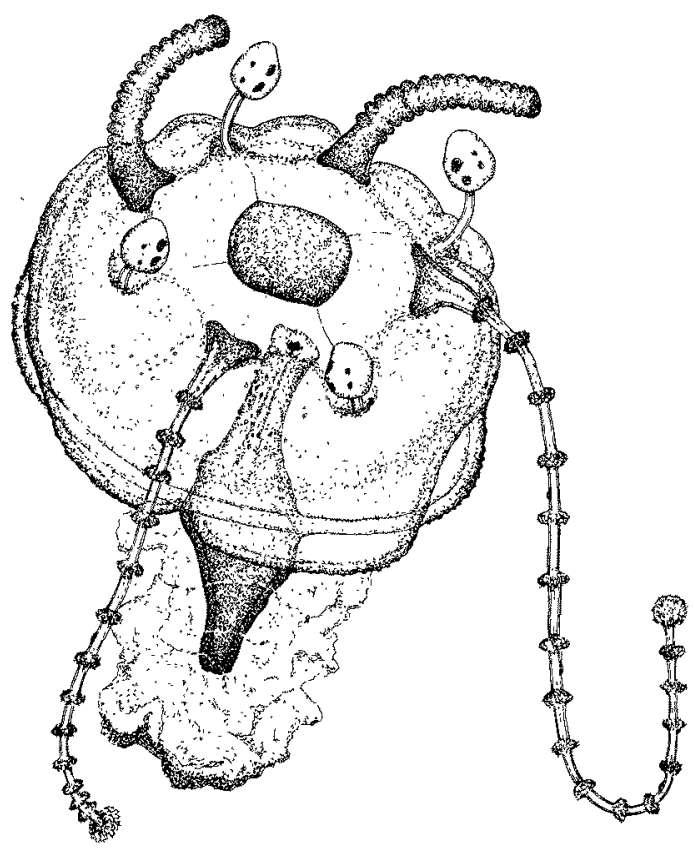

Abb. 20: Tripedalia cystophora, Metamorphose, Endstadium, Schrägaufsicht. Peridermbecher geschrumptt. Querdurchmesser des Schirms $1,0 \mathrm{~mm}$. (Zeichnung: F. K. Heckmann)

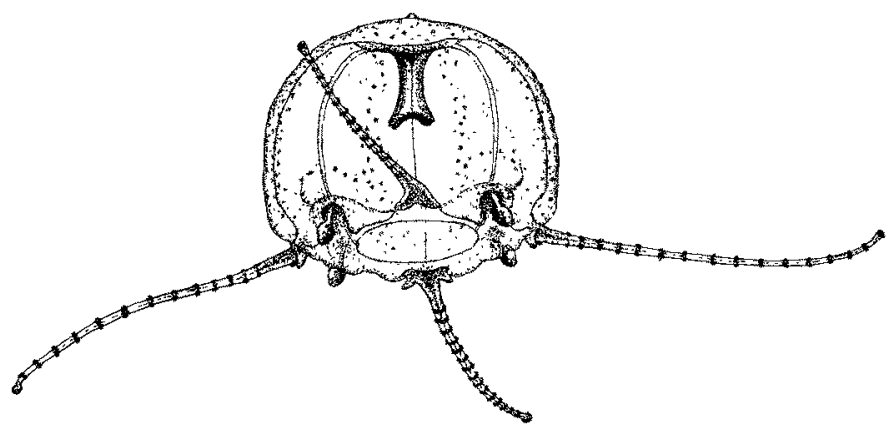

Abb. 21: Tripedalia cystophora, Jungmeduse nach beendeter Metamorphose. Schirmdurchmesser 1,6 mm, Höhe 1,4 mm. (Zeichnung: F. K. HeCKMANN)

tikale Faltung des Entoderm und die Bildung von 4 Längsfalten. Daher entstehen im Querschnitt 4 anfangs offene Entodermtaschen. Die "Septen" zwischen diesen Taschen entsprechen den äußerlich sichtbaren Längsfalten des Anfangsstadiums der Metamorphose (Abb. 18a). Durch die von oben nach unten verlaufende Verwachsung der Ento- 
dermfalten werden die Gastraltaschen verschlossen. (b) Wie schon erwähnt, erfolgt im Umkreis des Mundkegels eine ektodermale Einsenkung, die anfangs ringförmig erscheint. Im Inneren aber wachsen von dieser Einsenkung ausgehend 4 sich später vereinigende Einstülpungen nach unten, worauf die Entstehung der ektodermalen Epithe-

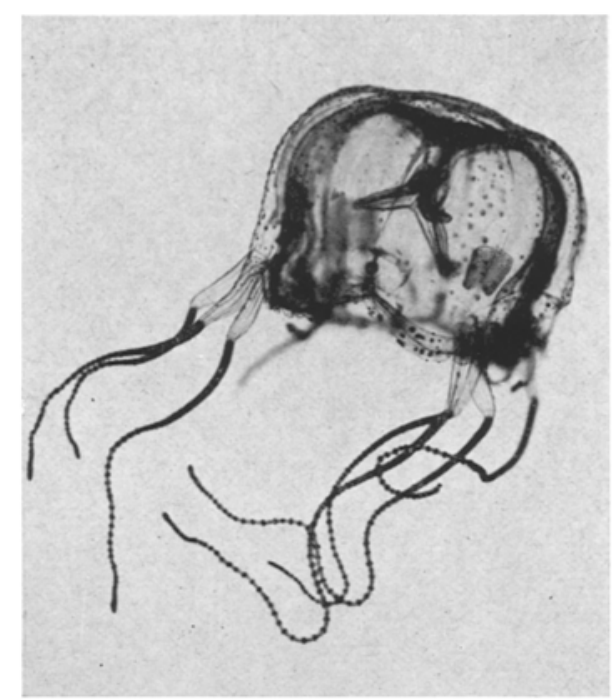

Abb. 22: Tripedalia cystophora, Kulturmeduse kurz vor völliger Reife; in der rechten Schirmhälfte sind dic paarigen Gonaden deutlich erkennbar

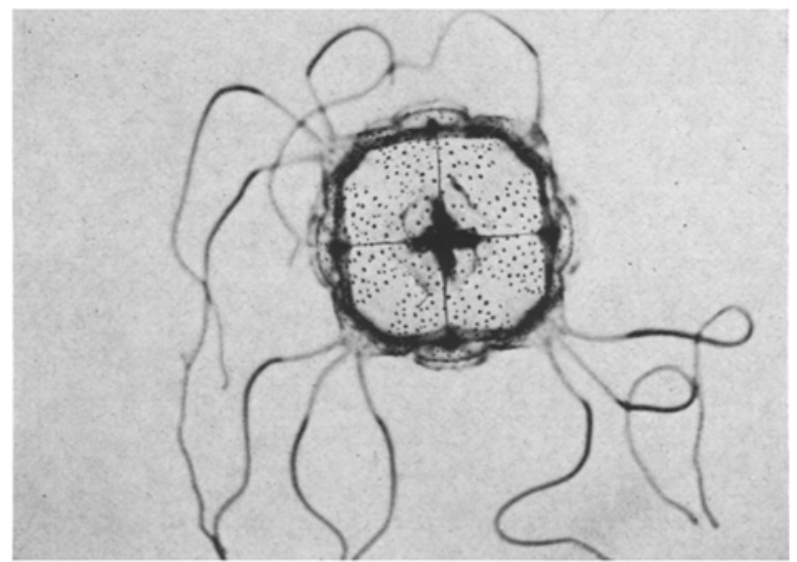

Abb. 23: Tripedalia cystophora, Aufsicht auf den apikalen Schirmpol einer Meduse zur Demonstration des vierstrahligen Musters der Nesselwarzen der Exumbrella

lien der Subumbrella und des sich bildenden Mundrohres zurïckzuführen ist. Wieweit der Mundkegel des Polypen in die Differenzierungsprozesse einbezogen wird, läßt sich noch nicht angeben. Bei einer Temperatur von 25 bis $27^{\circ} \mathrm{C}$ dauert der gesamte Prozeß der Metamorphose 5 bis 6 Tage. 
Die junge Meduse (Abb. 21) läßt sofort die für alle Medusen zutreffende Umkehr der Lageorientierung erkennen und schwimmt mit dem Apikalpol voran. Ihren 4 Tentakeln fehlen zunächst noch die Pedalien der Basalteile. Bereits am 2. oder 3. Tage nach beendeter Metamorphose erscheinen beiderseits der Tentakelbasen kleine Vorwölbungen, aus denen die beiden anderen Tentakel jeder der 4 interradial gelegenen Tentakelgruppen auswachsen. Nach etwa 8 Tagen haben die Sekundärtentakel die gleiche Größe

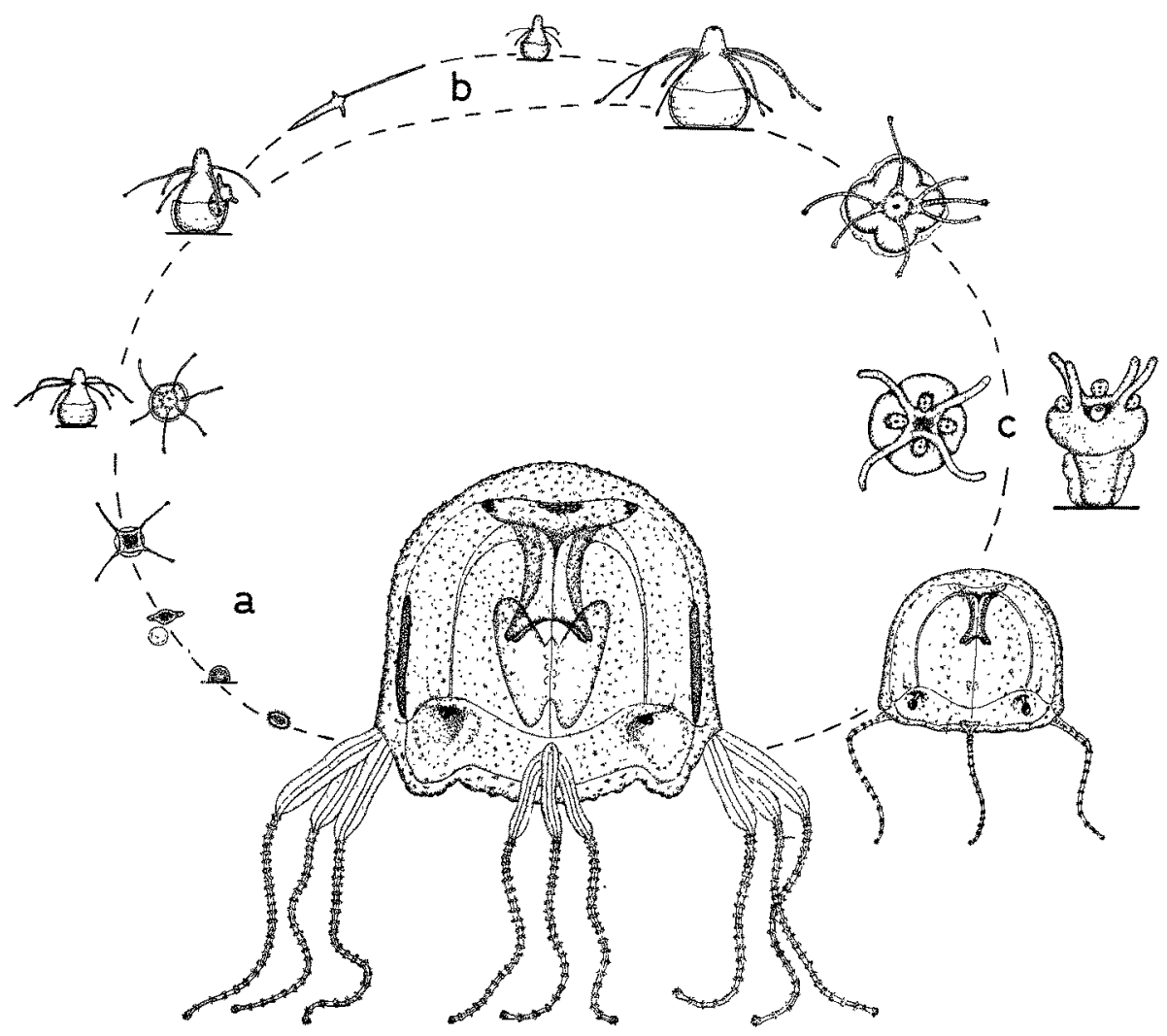

Abb. 24: Tripedalia cystophora, Schema des vollständigen Lebenskreislaufes. a Entwicklung der Planula zum jungen Primärpolypen; b Phase der asexuellen Vermehrung des Polypen durch seitliche Knospung, c Metamorphose des Polypen in die Meduse, links Aufsicht, rechts Seitenansicht. (Nach Werner, 1973b; Fig. 9, p. 52. Mit Erlaubnis des Herausgebers von Publs. Seto mar. biol. Lab.)

wie die Primärtentakel, so daß die für jeden Quadranten zutreffende Dreizahl erreicht ist. Die Basis formt sich allmählich zu den im Querschnitt flachovalen Pedalien um. Die Tentakel sind moniliform, das heißt, daß ihre Nesselzellen zu Ringen angeordnet sind. Charakteristisch ist auch der Besatz der Exumbrella mit Nesselzellen, der sie mit Warzen übersät erscheinen läßt. Die Aufnahme einer älteren Meduse läßt erkennen, daß die Nesselwarzen der Exumbrella in einem regelmäßigen vierstrahligen Muster 
angeordnet sind (Abb. 22, 23). Gastralfilamente fehlen der Jungmeduse noch. Sie entstehen in Form von 4 Büscheln erst später in den Interradien der Magenwandung. Ferner ist zu erwähnen, daß das Velarium, das dem Velum der Hydroidmedusen entspricht, noch keine Kanäle enthält, und daß das Frenulum, die zarthäutige Stützleiste der Subumbrella in den Perradien, bei der Jungmeduse nur eben als kurze Leiste am Schirmrand erkennbar ist. Bei der erwachsenen Meduse verläuft das Frenulum bis zum Ansatz des Mundrohres. Gonadenanlagen sind bei der Jungmeduse noch nicht vorhanden und werden erst später sichtbar. Im Schema des Lebenskreislaufes der Abbildung 24 sind die wichtigsten Phänomene der Lebensgeschichte von Tripedalia nochmals zusammenfassend dargestellt. Uber den zeitlichen Ablauf gibt die Tabelle 1 Auskunft.

Tabelle 1

Tripedalia cystophora. Dauer der Entwicklungsphasen in den Laboratoriumskulturen bei $25-27^{\circ} \mathrm{C}$

\begin{tabular}{|lcccc|}
\hline $\begin{array}{l}\text { Entwicklungs- } \\
\text { phase }\end{array}$ & $\begin{array}{c}\text { Eifurchung und Entwick- } \\
\text { lung zur Planula in der } \\
\text { Muttermeduse }\end{array}$ & $\begin{array}{c}\text { Planktische Phase } \\
\text { der Planula }\end{array}$ & $\begin{array}{c}\text { Primärpolyp bis Beginn } \\
\text { der Knospenbildung }\end{array}$ \\
\hline Dauer & 4 Tage & 2-3 Tage & 5-6 Wochen \\
\hline $\begin{array}{l}\text { Entwicklungs- } \\
\text { phase }\end{array}$ & $\begin{array}{c}\text { Entwicklung der } \\
\text { Knospe bis zur } \\
\text { Ablösung }\end{array}$ & $\begin{array}{c}\text { Primärpolyp bis } \\
\text { Beginn der } \\
\text { Metamorphose }\end{array}$ & Metamorphose & $\begin{array}{l}\text { Jungmeduse bis } \\
\text { Geschlechtsreife }\end{array}$ \\
\hline Dauer & 2-3 Tage & 10-12 Wochen & 5-6 Tage & 8-12 Wochen \\
\hline
\end{tabular}

\section{Die Nesselzellausstattung}

Tripedalia cystophora verfügt über eine vielgestaltige Nesselzellausstattung. Auch wenn insgesamt nur ein Tricnidom von basitrichen Haplonemen, holotrichen Haplonemen und heterotrichen mikrobasischen Eurytelen* nachweisbar ist, so kommen diese drei Kategorien doch bei den verschiedenen Stadien und an ihren Organen in mehreren Formvarietäten und Größenklassen vor. Die Ergebnisse der qualitativen und quantitativen Untersuchungen sind in Tabelle 2 zusammengestellt; sie sind noch durch einige allgemeine und spezielle Befunde zu ergänzen, die aus der Tabelle nicht oder nur unvollständig hervorgehen.

* Diagnosen nach der Klassifikation durch WeILL (1934, vgl. WERNER, 1965), die sich im ganzen als brauchbar erwiesen hat und der die meisten neueren Autoren folgen. Auf Schwierigkeiten, in manchen Fällen zu einer einwandfreien Diagnose zu gelangen, hat besonders Sснмmт $(1969,1972)$ hingewiesen. Die Kritik dieses Autors am Werluschen System und seine Verbesserungsvorschläge berücksichtigen ausschließlich die Nesselzellverhältnisse der Anthozoa, Sie können daher vorerst nicht als allgemein verbindlich angesehen werden, zumal Sснмпт nicht wie $W^{\prime}$ EILL von der F o r m des Nesselapparates der entladenen Kapsel ausgeht, sondern von seiner Bewaffnung, was die theoretischen Definitionen und praktischen Diagnosen bei der lichtmikroskopischen Untersuchung (Phasenkontrast, Interferenz nach Nomarski) nicht eben erleichtert. 
(a) Die Nesselzellen von Tripedalia sind mit einem Cnidocil und die Nesselkapseln mit einem Operculum versehen, die in ihrem strukturellen Aufbau mit denen der Nesselzellen bzw. Nesselkapseln bei den Scyphozoen und Hydrozoen übereinstimmen. Wie später noch zu zeigen ist, gleichen die Nesselkapseln von Tripedalia mehr denen der Hydrozoa; auch wenn es sich um gemeinsame Kategorien handelt, so lassen sich doch in Struktureigenschaften Unterschiede gegenüber den Nesselkapseln der Scyphozoa erkennen.

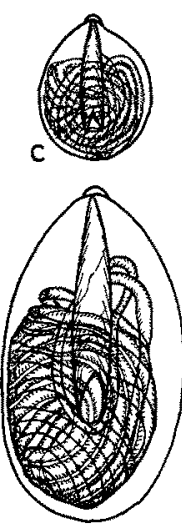

a

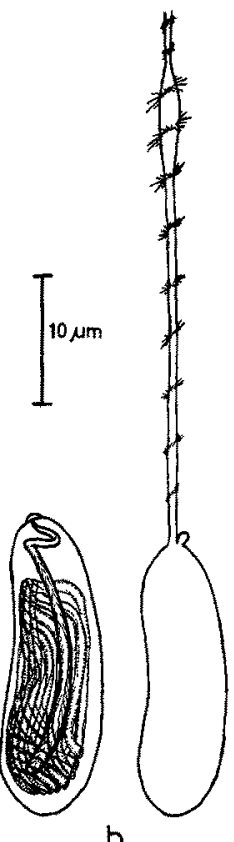

b
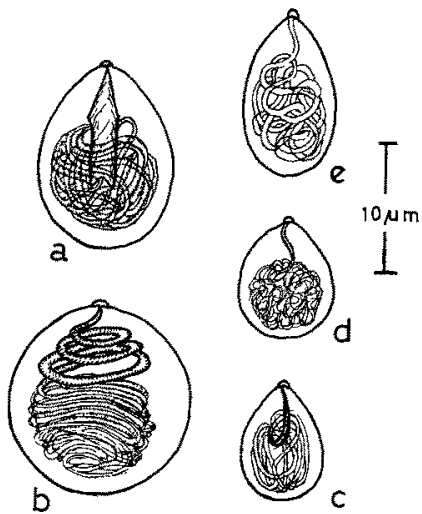

Abb. 25 a-c: Tripedalia cystophora, Cnidom des Polypen. a ovoide, b schlanke heterotriche mikrobasische Eurytele des Endteils der Tentakel, c rundliche Eurytele aus der Körperepidermis

Abb. 26 a-e: Tripedalia cystophora, Cnidom der Meduse; a ovoide heterotriche mikrobasische Eurytele, b runde holotriche Haploneme, c basitriche Haploneme, d holotriche Haploneme mit enggeknäueltem Nesselschlauch, e holotriche Haploneme mit lockerem Nesselschlaud. (Weitere Erläuterungen im Text)

(b) Polyp und Meduse von Tripedalia weisen charakteristische Unterschiede des Cnidoms auf, da der Polyp nur eine Kategorie besitzt, die Meduse aber drei. Beiden Generationen gemeinsam sind die heterotrichen mikrobasischen Eurytelen. Beim Polypen ist diese Kategorie in 3 Formtypen und 4 Größenklassen vertreten. Im Endteil der capitaten Tentakel findet sich in geringer Zahl ( 0 bis 5 ) einmal der bei Scypho- und Hydrozoen häufige ovoide Typ mit kurzem gedrungenem Achsenkörper bzw. Schaft der unentladenen bzw. entladenen Kapsel (Abb. 25a). Die Mehrzahl der Nesselkapseln des Tentakelendes (ca. 20 bis 40 ) aber gehört einem Formtyp an, der sich durch die schlanke, bananenähnliche Form der ganzen Kapsel und die schlanke, langgestreckte Form des Achsenkörpers bzw. Schaftes auszeichnet (Abb. 25b). Durch die erwähnten 


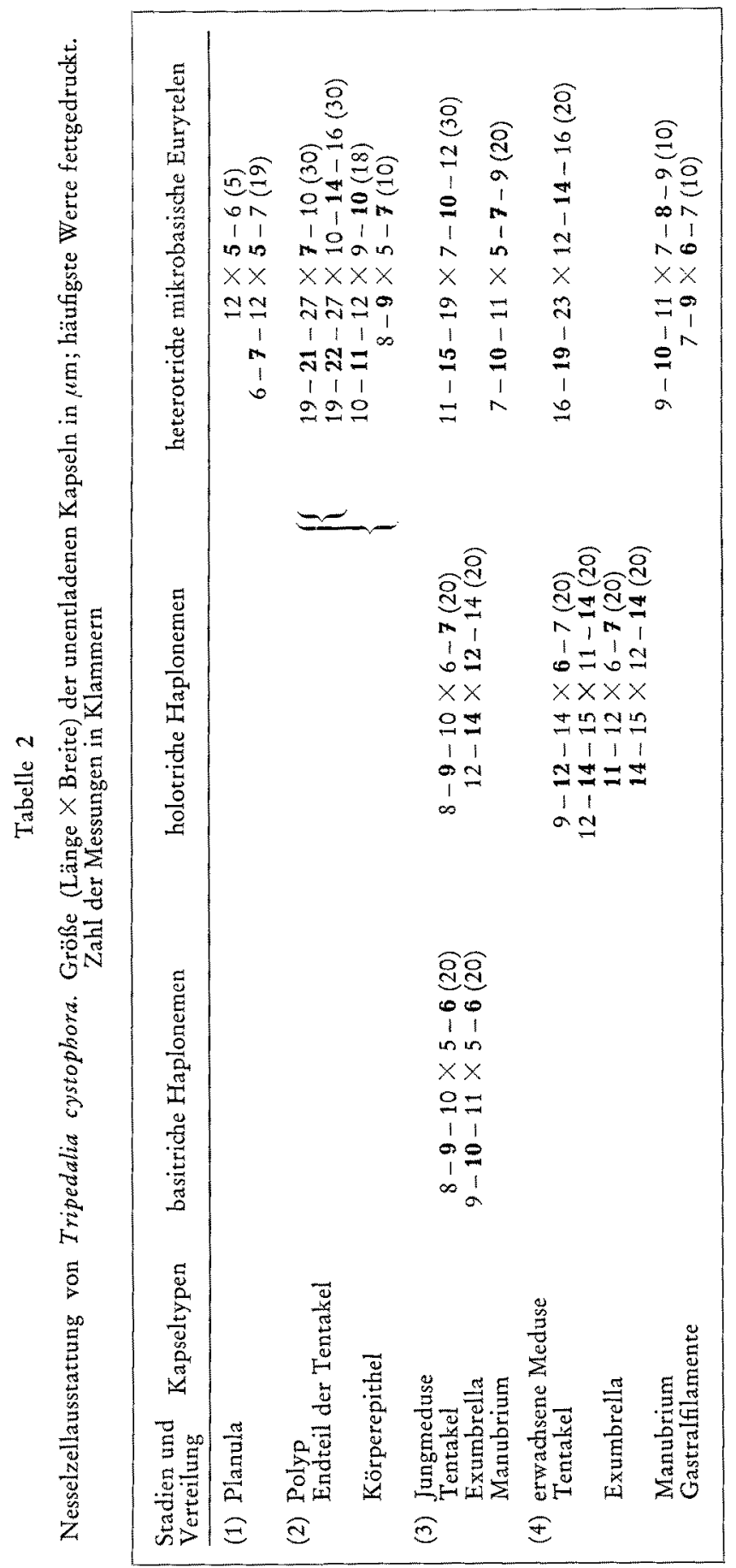


Eigenschaften ist dieser Formtyp der Kategorie der mikrobasischen Mastigophoren sehr ähnlich, und es war anfangs schwierig, zu einer einwandfreien Diagnose zu gelangen. Außerdem erwies sich dieser Typ im Lebendquetschpräparat als recht stabil, so daß man ihn nur selten im entladenen Zustand zu Gesicht bekam. Mit dem kleinen Kunstgriff, dem hungrigen Polypen einen Artemia-Nauplius darzubieten, lassen sich die Nesselkapseln auf natürliche Weise und ohne chemische Veränderung des Mediums zur Explosion bringen. Im Quetschpräparat des so getöteten Nauplius läßt sich dann die Form des Nesselapparates nach der Entladung einwandfrei ermitteln. Dabei zeigte sich, daß der Endabschnitt des Schaftes doppelt so dick ist wie seine Basis und daß sich der Nesselschlauch an der Übergangsstelle deutlich verdünnt. Daher muß dieser Formtyp nach der Definition Weills (1934) zu den Eurytelen gerechnet werden. Mit Fig. 67 (p. 75) bildet WeILL einen ähnlichen Typ ab, der im entladenen Zustand ebenfalls den schlanken Schaft aufweist. Außerdem wurde ich in der Diagnose durch die Befunde von Boullion (1974) bestätigt, der bei dem Hydroidpolypen Paracoryne buvei den gleichen Formtyp entdeckt und beschrieben hat. Auch bei dieser Art kommt gleichzeitig der Formtyp der Eurytele mit kurzem, dickem Achsenkörper bzw. Schaft vor (Boumlon, 1974; p. 27, Fig. 12, Teilfig. 3, 4 und 5, 6). Beim Polypen von Tripedalia sind außerdem Eurytelen mit einer rundlichen Kapselform zu beobachten, die in zwei Größenklassen auftreten (Abb. 25c). Sie liegen in der Körperepidermis unterhalb des Tentakelkranzes, wo sich die Bildungszone für alle Kapseltypen befindet, wo also auch die Formtypen der im Endabschnitt der Tentakel vorhandenen Nesselkapseln in geringer Zahl anzutreffen sind.

(c) Es ist bemerkenswert, daß die Eurytelen des Formtyps der Abbildung 25b wohl beim Polypen, nicht aber bei der aus ihm hervorgehenden Meduse nachzuweisen sind. Dieser Typ wird daher im Verlauf der Metamorphose ausgeschieden. Die Jungmeduse verfügt nur über den ovoiden Formtyp der Eurytelen mit kurzem Achsenkörper (Abb. 26a) und überdies über die weiteren Kategorien der basitrichen und holotrichen Haplonemen (Abb. 26c, b, d). Die basitrichen Haplonemen kommen zusammen mit großen, annähernd runden holotrichen Haplonemen in den Nesselwarzen der Exumbrella vor. Die ringförmigen Nesselbatterien der Tentakel enthalten in annähernd gleichen Quantitäten ovoide Eurytelen und kleinere holotriche Haplonemen eines ovoiden Formtyps, der in unentladenem Zustand durch die dichte knäuelartige Aufwindung des Nesselschlauches kenntlich ist (Abb. 26d).

Die erwachsene Meduse verfügt über den gleichen Formtyp der Eurytelen wie die Jungmeduse; außerdem besitzt sie ebenfalls die großen rundlichen holotrichen Haplonemen und einen ovoiden Formtyp dieser Kategorie, der sich durch die lockeren Windungen des unentladenen Nesselschlauches auszeichnet (Abb. 26e). Der letztere Typ ist sowohl in den Nesselwarzen der Exumbrella wie in den Nesselringen der Tentakel anzutreffen. Basitriche Haplonemen und ovoide Holotrichen mit enggeknäueltem Nesselschlauch sind bei der erwachsenen Meduse nur sehr spärlich vertreten, spielen daher bei ihr praktisch keine Rolle mehr. An den Gastralfilamenten und den perradialen Kanten des Manubrium sind kleine ovoide Eurytelen mit kurzem Achsenkörper vorhanden. Ergänzend muß erwähnt werden, daß sowohl bei der jungen wie der erwachsenen Meduse die Mundlippen des Manubrium fast frei von Nesselzellen sind. 


\section{Bemerkungen zur Okologie von Tripedalia cystophora}

Die Meduse von Tripedalia cystophora unterscheidet sich in ihren ökologischen Ansprüchen von den anderen Cubomedusen-Arten, die vorwiegend im freien Wasser vor offenen Stränden vorkommen und allgemein als neritische Formen gelten. CoNANT (1898) hat die Meduse 1896 in einer geschützten Bucht des Kingston Harbor, Jamaica, entdeckt. In der vom freien Meer und dem übrigen Teil des Hafens durch eine Halbinsel teilweise abgeschlossenen Bucht liegen zahlreiche kleine Mangrove-Inseln, und landwärts geht sie in einen Mangrove-Sumpf über. Hier im flachen Wasser, zwischen den Stelzwurzeln der Mangroven und unter überhängendem Laubwerk, trat die Meduse während des Sommers in großen Mengen auf.

In ähnlichen Biotopen lebt die Meduse in den Küstengewässern von Puerto Rico, wo sie von Cutress 1969 in den großen Mangrove-Beständen westlich der Meeresstation La Parguera entdeckt wurde (vgl. p. 465 f.). Wie ich im November 1971 während eines Studienaufenthaltes an dieser Station selbst beobachten konnte, hält sich die Meduse in den Kanälen zwischen den Mangrove-Inseln und an deren Rand vorzugsweise im Halbschatten zwischen den äußeren Stelzwurzeln der Mangrove-Bäume auf. Auch hier ist die Wassertiefe gering, und der Boden besteht aus weichem Mud organischer Herkunft. Die Oberflächentemperatur schwankt im Jahresgang zwischen $25^{\circ}$ und $30^{\circ} \mathrm{C}$. Der Salzgehalt des Oberflächenwassers kann in Küstennähe nach starken Regengüssen bis auf 27-28\% absinken, schwankt jedoch normalerweise zwischen 34 und $38 \%$. Wenn auch vergleichende quantitative Untersuchungen noch nicht vorliegen, so darf doch aus den wenn auch nur grob skizzierten Milieufaktoren auf eine relativ große Toleranz der Meduse gegenüber den wichtigsten Außenbedingungen geschlossen werden. Diese Eigenschaft und die geringe Größe dürften die Ursache dafür sein, daß sich die Meduse vor allen anderen Arten im Laboratorium leicht hältern und nach den eigenen Untersuchungen leicht züchten läßt. Nur die Temperaturtoleranz dieser Art ist beschränkt, da sie unterhalb einer kritischen Grenztemperatur überhaupt nicht auftreten kann (s. u.); sie ist also auf die Tropen und Subtropen beschränkt. Der Vollständigkeit halber sei erwähnt, daß weitere Fundorte von den Philippinen (StIASNY, 1926) und von der Küste von Kyuschu, Japan (Uchida, 1970) bekannt sind.

Zur Okologie des Polypen lassen sich kaum zuverlässige Angaben machen, da er im freien Wasser noch nicht gefunden worden ist. Doch ist anzunehmen, daß er an den Stellen des häufigen Vorkommens der Meduse lebt, etwa im flachen Wasser an den Stelzwurzeln der Mangroven. Man geht daher wohl in der Annahme nicht fehl, daß er sich in seinen ökologischen Ansprüchen nicht allzu sehr von denen der Meduse unterscheidet. Allerdings bestehen nach den Laboratoriumsbeobachtungen Unterschiede in den Temperaturansprüchen der beiden Generationen, die sich auf die asexuelle Vermehrung des Polypen und seine Metamorphose in die Meduse beziehen. Der Polyp ist bei niederen Temperaturen von $20^{\circ}-22^{\circ} \mathrm{C}$ existenz- und reaktionsfähig und verharrt in diesem Temperaturbereich in der Phase der asexuellen Vermehrung. Die Umwandlung in die Meduse setzt erst oberhalb einer kritischen Temperatur von etwa $22^{\circ}$ bis $24^{\circ} \mathrm{C}$ ein, wodurch die Existenz der Medusengeneration an höhere Temperaturen oberhalb dieser Grenze gebunden ist. Wird der Polyp aus der niederen in die höhere Temperaturstufe versetzt, so wird zuerst die asexuelle Vermehrung durch Knospen- 
bildung beschleunigt, bis schließlich die Metamorphose eintritt. Auch bei dieser Art ist die Temperatur eine notwendige, aber keine hinreichende Bedingung: Die Metamorphose kann nur im höheren Temperaturbereich erfolgen; aber nicht immer, wenn diese Bedingung erfüllt ist, muß auch stets die Metamorphose einsetzen. Dafür ist vielmehr der Zustand der inneren Bereitschaft Voraussetzung, der von Eigenschaften wie Alter, Größe, Ernährung abhängt.

Der Nachteil der vollständigen Metamorphose, die die Existenzform der Polypengeneration beendet, wird durch die vorangegangene asexuelle Vermehrung ausgeglichen. Nach allen Beobachtungen machen sowohl Primär- wie Sekundärpolypen stets zuerst die Phase der Knospung durch, die, wie mehrfach erwähnt, der Vergrößerung des Bestandes dient und durch die verhindert wird, daß der Bestand an Polypen in einem bestimmten Zeitraum und in einem bestimmten Biotop durch ihre Metamorphose voilständig verschwindet. Allerdings dürfte die Gesamtzahl der von einem Polypen während seines ganzen Lebens erzeugten Knospen bzw. Sekundärpolypen bei höheren Temperaturen, etwa bei $25^{\circ}-28^{\circ} \mathrm{C}$ geringer sein als bei niedrigeren Temperaturen, weil die Metamorphose früher eintritt. Daher dürfte die Populationsstärke der Polypengeneration in der wärmsten Jahreszeit, in der die Medusengeneration ihr Maximum erreicht, am geringsten sein. Der Ausgleich erfolgt durch die sexuelle Vermehrung der Medusen, die eine neue Polypengeneration entstehen läßt.

Die Fähigkeit des erwachsenen Polypen, sich unter ungünstigen Bedingungen vom Substrat ablösen und kriechend einen neuen Anhefungsort suchen zu können, dürfte insofern von ökologischer Bedeutung sein, als sie bestandserhaltend wirkt. Zwar ist die Kriechgeschwindigkeit gering; doch dürtte ein Polyp beispielsweise in der Lage sein, sich bei Sauerstoffmangel am Substrat kriechend, etwa an einer Mangrove-Stelzwurzel aus bodennahen Wasserschichten nach oben in die Zonen besserer $\mathrm{O}_{2}$-Versorgung zu bewegen. In ähnlicher Weise dürfte sich die weitere Fähigkeit des Polypen positiv auswirken, sich unter ungünstigen Bedingungen zu encystieren und unter vollständiger Kontraktion der Tentakel in ein kugeliges inaktives Stadium zu verwandeln, das vollständig von einer geschlossenen feinen Peridermhülle umgeben ist. In diesem Zustand, in dem vermutlich die Stoffwechselaktivität herabgesetzt ist, ist das Ruhestadium in der Lage, ungünstige Lebensbedingungen zu überdauern. Bei Eintritt normaler Lebensbedingungen, im Kulturversuch bei regelmäßiger Zufuhr von frischem $\mathrm{O}_{\Im}$-reichem Wasser, streckt der Polyp sich aus, durchbricht die Peridermhülle und hat bei ausreichender Nahrungszufuhr alle Fähigkeiten des Normalpolypen. Mehrfach wurde beobachtet, daß ein solcher "reaktivierter" Polyp sich loslöst und einen anderen Anheftungsort aufsucht (vgl. p. 482).

Es ist von Interesse, daß auch der Polyp der verwandten Art Carybdea spec. (p. 466) die Fähigkeit hat, sich unter ungünstigen Bedingungen, etwa bei Ubervölke.. rung einer Kulturschale, in ein inaktives Stadium umzuwandeln. Bei dieser Art löst sich der abgekugelte Polyp vom Substrat vollständig $a b$, ohne sich zu encystieren, ohne sich also mit einer Peridermhülle zu umgeben. In der Kulturschale liegen solche Stadien passiv am Boden. Setzt man sie in frisches Wasser um, so strecken sie nach einigen Tagen den Körper und die Tentakel aus, heften sich erneut an und haben bei entsprechender Ernährung ebenfalls wieder alle Fähigkeiten eines normalen Polypen. Im freien Wasser besteht für solche abgelösten, inaktiven Stadien die Möglichkeit, daß sie 
passiv in Zonen besserer Lebensbedingungen verdriftet werden, in denen sie in den aktiven Zustand zurückkehren können. Nach diesen Beobachtungen kann angenommen werden, daß sich die Polypen beider Arten durch ein relativ breites Spektrum ihrer Toleranzeigenschaften auszeichnen, was sie in jedem Fall zu leicht zu züchtenden Kulturformen macht.

\section{DISKUSSION}

Nach den hier mitgeteilten Resultaten der Untersuchungen an Tripedalia cystophora kann die Lebensgeschichte einer Cubomedusenart nunmehr in allen wesentlichen Phasen als bekannt gelten. Dabei ist hervorzuheben, daß sich die meisten Resultate sozusagen von selbst ergaben, nachdem einmal die erste und schwierigste Hürde genommen war, nämlich die Aufzucht der Primärpolypen aus Planulae. Auch darf angenommen werden, daß die Entwicklung anderer Cubomedusenarten in ähnlicher Weise verläuft. Ein Hinweis ist bereits mit den Parallelbeobachtungen über die Morphologie und Entwicklung des Polypen der Carybdea-Art gegeben, der an der Küste von Puerto Rico aufgefunden wurde.

Die wohl auffallendste Erscheinung im Lebenszyklus von Tripedalia ist die vollständige Metamorphose des Polypen in eine einzige Meduse. Es ist zu betonen, daß es sich bei der vorliegenden Form der Umwandlung um eine wirkliche Metamorphose handelt, nicht etwa um eine abgewandelte Strobilation oder einen speziellen Knospungsprozeß. Diese Erscheinung ist deswegen so bemerkenswert, weil sie in eindeutiger Weise demonstrieren kann, daß eine Meduse generell nichts anderes ist als ein losgelöster, in Anpassung an das pelagische Dasein umgeformter Polyp. Es sei erneut daran erinnert (vgl. Werner, 1973b; p. 54), daß die Vertreter der klassischen Morphologie vor rund 100 Jahren, wie Weismand, Haeckel, die Brüder Hertwig und andere, zum gleichen Ergebnis gekommen waren, und zwar auf Grund der Homologie der Strukturen. Bei Tripedalia aber spielt sich das zur Diskussion stehende Phänomen, das vorher nur der theoretischen Spekulation zugänglich war und einem langen Zeitraum der Evolution zuzuschreiben ist, innerhalb weniger Tage vor den Augen des Zuschauers $a b$ und kann durch das einfache Mittel der Temperaturerhöhung jederzeit ausgelöst werden.

Andererseits bleibt zu fragen, ob es sich bei der Metamorphose von Tripedalia um ein primitives, ursprüngliches Merkmal handelt, oder ob es nicht doch als abgeleitetes Merkmal einer progressiven Evolution zu betrachten ist, in dem sekundär ein ursprünglicher, evolutionistisch alter Prozeß in kürzester Zeitspanne wiederholt wird. Eine eindeutige Antwort auf diese Frage zu geben, erscheint schwierig. Die monodiske Strobilation, wie sie bei den Rhizostomeae der Scyphozoa vorkommt, bei der aber kein basaler regenerationsfähiger Restkörper des Polypen übrig bliebe, wäre eine denkbare Form der Medusenentstehung, die im Endeffekt einer vollständigen Metamorphose gleichkäme. Jedoch sind in Wirklichkeit die Teilprozesse einer monodisken Strobilation wie auch ihr Endprodukt, die scheibenförmige Ephyra, von den Umformungsvorgängen der Metamorphose bei Tripedalia und von der entstandenen Meduse grundverschieden. 
In jedem Fall findet die heute geltende Auffassung, daß der Polyp die primäre Generation und daß ein Polyp die Urform aller rezenten Cnidaria darstellt, durch die Erscheinung der Metamorphose des Cubopolypen eine wirksame Unterstützung. Man kann daher den Polypen nicht mehr als Larvalform betrachten. Daß er sich bei den meisten Cnidaria asexuell zu vermehren vermag, daß er also praktisch unbegrenzt existenzfähig ist, daß weiterhin stets die Meduse vom Polypen erzeugt wird, daß schließlich nach unseren Kenntnissen bei den Anthozoa nie eine Meduse existiert hat, sind weitere Gründe für die Richtigkeit dieser Auffassung.

Die Metamorphose von Tripedalia gestattet mit einem bestimmten Teilvorgang die Verifikation einer weiteren, vorher nur theoretisch abgeleiteten Annahme; sie bezieht sich auf die Umformung der Polypententakel in die Sinnesorgane der Meduse. Auf Grund ihrer Lage und Strukturen wurden die Sinnesorgane speziell der Scyphomedusen schon früher als umgewandelte Tentakel betrachtet; doch konnte sich diese Annahme meines Wissens nicht auf die unmittelbare Beobachtung eines realen Entwicklungsvorganges stützen, der mit der Bildung der Sinnesorgane der Cubomeduse vergleichbar ist. Wir sahen (p. 485), daß dabei die Tentakelenden resorbiert werden, daß aber die Tentakelbasis beim Aufbau der Sinnesorgane verwendet wird.

Fragt man nach den allgemeinen Konsequenzen der mitgeteilten Beobachtungen über die Lebensgeschichte von Tripedalia, so wird unmittelbar klar, daß sie die systematische Stellung der "Cubozoa " in entscheidender Weise beeinflussen und daß die bisherigen Vorstellungen (p. 462) einer Revision unterzogen werden müssen. Es dürfte keinem Zweifel unterliegen, daß sich der Polyp durch seinen radiärsymmetrischen Körperbau, durch das Fehlen aller tetrameren Strukturen, durch die capitate Beschaffenheit der Tentakel, durch die asexuelle Vermehrung mittels seitlicher Polypenknospung, durch die Kriechfähigkeit im erwachsenen Zustand, durch die direkte und vollständige Metamorphose in die Meduse eindeutig von allen rezenten Scyphopolypen unterscheidet. Nach den vorliegenden Kenntnissen besteht nur ein wesentliches Merkmal, in dem der Polyp von Tripedalia mit einem Scyphopolypen übereinstimmt, nämlich im Besitz von Muskelzellen (Myozyten) in der Mesogloea. Dieses Merkmal ist bei dem etwas größeren Polypen von Carybdea noch deutlicher ausgeprägt, wie die vergleichenden Untersuchungen von Chapman ergeben haben. Die Muskelzellen sind beim Cubopolypen aber nicht wie beim Scyphopolypen zu 4 einzelnen, in den Septen liegenden Muskelsträngen zusammengefaßt, sondern umgeben den Körper ringsum in zum Teil mehrschichtiger Lage. Ubrigens hat der Polyp von Carybdea eine weitere Eigenschaft mit dem Scyphopolypen gemeinsam, da seine Epidermis wie bei diesem mit schlagenden Geißeln besetzt ist, die dem Polypen von Tripedalia fehlen. Derartige Befunde sprechen dafür, daß Scyphopolyp und Cubopolyp auf gemeinsame Vorfahren zurückgehen. Diese Auffassung wird auch durch die weitere Beobachtung gestützt, daß der vorher radiärsymmetrische Polyp von Tripedalia während der Metamorphose tetramere Formen und Strukturen annimmt.

Wie steht es mit den Nesselzellverhältnissen? Durch die Arbeiten früherer Autoren (vgl. besonders WerLL, 1934, und die Zusammenfassung bei WERNER, 1965; ferner die neueren Arbeiten von Scrmidr 1969, 1972) ist bekannt, daß die Nesselzellausstattung allgemein taxonomische Bedeutung hat, insofern als der Besitz spezieller Kapseltypen positive Aussagen ermöglicht, die das nach morphologischen Merkmalen auf- 
gebaute System stützen und in zweifelhaften Fällen klären können. Daher lag es nahe, im Hinblick auf die systematische Problematik die Nesselzellausstattung von Tripedalia mit den Verhältnissen bei den Scyphozoa und Hydrozoa zu vergleichen und nach Gemeinsamkeiten und Unterschieden zu suchen. Die Scyphozoa besitzen nur wenige Kategorien von Nesselkapseln, nämlich atriche Haplonemen, holotriche Haplonemen und heterotriche mikrobasische Eurytelen (WeILl, 1934; Werner, 1965)\%. Die Hydrozoen dagegen haben von allen Klassen die größte Zahl verschiedener Kategorien, nämlich 23, und haben überdies klasseneigene Typen, während die Scyphozoa nur Kapseltypen besitzen, die auch bei den Hydrozoa vorkommen.

Nach den vorliegenden Befunden hat Tripedalia mit den Scyphozoa die Kategorien der holotrichen Haplonemen und heterotrichen mikrobasischen Eurytelen gemeinsam und unterscheidet sich von ihnen durch den Besitz der basitrichen Haplone-men, die andererseits bei den Hydrozoa nicht selten sind. Der genauere Vergleich der gemeinsamen Kategorien, der vorhandenen Formtypen und ihrer strukturellen Eigenschaften führte weiterhin zu folgenden Resultaten. (a) Die Kategorie der holotrichen Haplonemen ist bei den Scyphozoa nach WeILl (1934; p. 573, Fig. 30a, b) einmal durch einen rundlichen Formtyp vertreten, der nach Kapselform und Aufrollung des Nesselschlauches mit dem runden Typ von Tripedalia (Abb. 26b) übereinstimmt. Außerdem haben die Scyphozoa den ovoiden Formtyp der Holotrichen, der häufiger vorkommt und von Papenfuss (1936) für mehrere Arten der Semaeostomeae beschrieben und abgebildet wurde. Nach den eigenen Beobachtungen ist dieser ovoide Formtyp der Holotrichen weiterhin typisch für die Polypen und Medusen der Coronatae. Charakteristisch ist, daß bei dieser Varietät der Nesselschlauch der unentladenen Kapsel eine annähernd symmetrische Aufrollung quer oder schräg zur Längsachse der Nesselkapsel hat. Die beiden beschriebenen ovoiden Typen der Holotrichen von Tripedalia sind durch die unregelmäßige Aufrollung des Schlauches deutlich verschieden. (b) Die schlanken Eurytelen des Formtyps b (Abb. 25b), die bei Tripedalia auf die Polypengeneration beschränkt sind, wurden bei den Scyphozoa bisher nicht gefunden, wohl aber bei den Hydrozoa (p. 492). Die ovoiden und rundlichen Eurytelen der Scyphozoa zeigen ähnlich wie die ovoiden Holotrichen eine mehr oder weniger symmetrische und regelmäßige Anordnung des Schlauches der unentladenen Kapsel, wie ihre bildliche Darstellung bei Papenfuss (1936; vgl. Russell 1970; p. 9, Textfig. 5) erkennen läßt. Dadurch sind die Eurytelen der Scyphozoa von der gleichen Kategorie der Hydrozoa und von Tripedalia gut unterscheidbar, weil bei den letzteren der Nesselschlauch asymmetrisch und unregelmäßig aufgerollt ist. Berücksichtigt man daher die evolutionistisch interessante Tatsache, daß die Nesselzellausstattung der Scyphozoa sowohl hinsichtlich der Zahl der vorhandenen Kategorien wie auch hinsichtlich der strukturellen Eigenschaften der Nesselkapseln einfach und gleichförmig ist, so fïhrt der Vergleich zu dem Resultat, daß im Cnidom von Tripedalia zwar Gemeinsamkeiten mit den Scyphozoen

* Salvini Plawen (1966) hat für eine neu entdedzte Scyphozoen-Art aus dem Mesopsammal der Adria noch das Vorkommen von telotrichen makrobasischen Eurytelen angegeben. Wegen der Länge des Schaftes der entladenen Kapsel, die nach seinen Maßangaben (p. 174, Fig. 12) etwa das Doppelte der Kapsellänge beträgt, gehört indes dieser spezielle Formtyp nach der Definition Wencs (1934) ebenfalls zu den m i k r o basischen Eurytelen. 
vorhanden sind, daß aber die Unterschiede überwiegen und daß größere Übereinstimmungen sowohl in den vorhandenen Kategorien wie auch in den Form- und Struktureigentümlichkeiten mit den Hydrozoen bestehen.

Uber die Nesselzellverhältnisse der Cubomedusen liegen bislang nur wenige Literaturangaben vor. Nach den Arbeiten früherer Autoren (Southcott \& Kingston, 1959; Kingston \& Southcott, 1960; Cleland \& SouthcotT, 1965; Halstead, 1965 ; Southcott, 1967; Calder \& Peters, 1975), nach den hier mitgeteilten sowie weiteren eigenen, unpublizierten Untersuchungen, wurden bei den Cubozoa bislang folgende 5 Kategorien von Nesselkapseln beobachtet: basitriche Haplonemen, holotriche Haplonemen, mikrobasische Mastigophoren, heterotriche mikrobasische Eurytelen und Stenotelen. Von besonderer Bedeutung ist das Vorkommen des hochspezialisierten Typs der Stenotelen, der von Curress (unpubliziert) bei dem Polypen von Carybdea entdeckt wurde, weil er bislang nur von den Hydrozoa bekannt war, so daß er als klasseneigener Typ gegolten hatte (Werner, 1965; Tab. 2, p. 19). Diese Befunde bestätigen und vervollständigen das an Tripedalia erzielte Resultat, daß in den Nesselzellverhältnissen der Cubozoa deutliche Unterschiede gegenüber den Scyphozoa bestehen. Andererseits ist hervorzuheben, daß die Cubozoa nach den bisherigen Kenntnissen über keinen Kapseltyp verfügen, der ausschließlich bei ihnen vorkommt. Sie gleichen in dieser Hinsicht den Scyphozoa, übertreffen diese aber mit der Zahl der vorhandenen Kate-

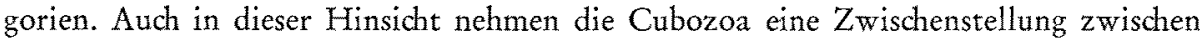
den Scyphozoa und Hydrozoa ein.

Auf Grund der Kenntnis von Bau und Lebensgeschichte der Art Tripedalia cystophora und der gewonnenen Einsichten über die systematische Stellung der Cubozoa erscheinen jetzt auch die morphologischen Besonderheiten der Cubo m e d u s en, die sie früher zu "schwarzen Schafen“ unter den Scyphomedusen gemacht hatten, in einem neuen Licht. Die Würfel- bis Glockenfonm des Schirms, der Besitz des Velariums und der anderen Schirmrandstrukturen, das Vorhandensein eines Nervenrings und hochentwickelter Sinnesorgane, das unterschiedliche Schwimmverhalten mit einer hohen Frequenz der Schirmpulsationen, das sie zu äußerst gewandten und schnellen Schwimmern macht, das erst neuerdings entdeckte Paarungsverhalten mit der Bildung von Spermatozeugmen und der direkten Ubertragung yon Spermatophoren auf das Weibchen: Alle diese Merkmale sprechen eindeutig dafür, daß die Cubomedusen keine Scyphomedusen sind, ebenso wie ihr Polyp kein Scyphopolyp ist.

Andererseits muß berücksichtigt werden, daß die Cubomedusen mit den Scyphomedusen einige Merkmale gemeinsam haben. Zu nennen sind: der Besitz von Gastralfilamenten, die entodermale Entstehung der Gonaden und das Ausstoßen der Geschlechtsprodukte aus dem Magenraum und Mund. Ferner ist der Besitz von geschlossenen Gastraltaschen ein Merkmal, das die Cubomedusen mit den Scyphozoa teilen, wo es bei den Stauromedusen vorkommt. Das gleiche gilt für das Vorhandensein von 4 Paaren Gonaden und ihre Anordnung; sie liegen jederseits eines Gastralseptums. So ist es erklärlich, daß früher versucht worden ist, die Cubo- und Stauromedusen in einen engeren verwandtschaftlichen Zusammenhang zu bringen (UCHIDA 1929, dort weitere Literatur). Das ist jetzt nicht mehr möglich, weil die Beobachtungen über die Lebensgeschichte von Tripedalia dagegen sprechen, woraus UCHIDA (1973) die Konsequenzen gezogen hat. Auch wenn hier nicht auf Einzelheiten eingegangen werden kann, 
so ist doch zu erwähnen, daß die Stauromedusen im Besitz des Coronarmuskels ein untrügliches Merkmal der Scyphomedusen aufweisen, das den Cubomedusen fehlt.

Die separate Stellung der Cubozoa manifestiert sich in einem weiteren wichtigen Merkmal, nämlich in der Entodermbildung während der Embryonalentwicklung. Sie erfolgt bei den Scyphozoa bekanntlich allgemein durch Invagination. Für die Cubozoa beschränkt sich die Kenntnis der Entodermentstehung auf wenige kurze Bemerkungen von Conant (1898) und die Resultate der Untersuchungen von OKADA (1927), auf die einleitend schon hingewiesen wurde. CoNANT hat die Entwicklung der Geschlechts produkte in den Gastraltaschen des Weibchens von Tripedalia beobachtet, die er unter der Bezeichnung "floating masses of cells" (p. 25 f.) beschreibt. Das von ihm abgebildete Stadium (Fig. 71) stellt offensichtlich eine Sterrogastrula dar, die im Inneren Zellen enthält, ohne daß Anzeichen einer Invagination erkennbar wären. ОкаDA (1927, p. 246), der die Befunde ConANT's zitiert, vermutet daher mit Recht, daß die Entodermzellen durch Delamination entstanden und eingewandert sind. In jedem Fall entsteht bei Carybdea rastoni nach den Resultaten der Untersuchungen von OKADA selbst das Entoderm durch multipolare Delamination, also durch Teilung und Einwanderung der Zellen des Ektoderms der Blastula und durch nachfolgende Teilungsschritte der eingewanderten Zellen (vgl. ReNsch, 1959, p. 106). Es liegt damit ein Entwicklungsgeschehen vor, das von der typischen Entodermbildung der Scyphozoa verschieden ist, dagegen in der Entodermbildung der Hydrozoa in ähnlicher oder abgewandelter Form die Regel ist. Wenn auch sehr zu wünschen ist, daß ebenso wie die Entodermbildung so auch alle anderen Phasen der Lebensgeschichte bei weiteren Arten untersucht werden, so sprechen doch auch die bisherigen entwicklungsgeschichtlichen Kenntnisse gegen ein Verbleiben der Cubozoa in der Klasse Scyphozoa.

Ebenso sind die Unterschiede sowohl zwischen dem Cubopolypen und dem Hydroidpolypen wie auch zwischen der Cubomeduse und der Hydroidmeduse so er heblich, daß die Alternative, die Cubozoa in die Klasse Hydrozoa einzureihen, von vornherein ausscheidet. Wenn auch der Cubopolyp in seiner äußeren Morphologie einem Hydroidpolypen recht ähnlich ist, so wird doch auch besonders durch die Ergebnisse der histologischen Analyse (Werner \& Chapman 1976, im Druck; Champman 1976, in Vorbereitung) bestätigt, daß entscheidende Unterschiede bestehen. Ein wichtiges Merkmal wurde bereits kurz genannt (p. 496): Das Muskelsystem des Polypen von Tripedalia besteht zum Teil aus reinen Myocyten, die in der Mesogloea liegen und den Körper ringsum in mehrschichtiger Lage umgeben. Bei den Hydrozoa aber besteht das Muskelsystem bekanntlich aus längsverlaufenden ektodermalen und querverlaufenden entodermalen Epithelmuskelzellen. Berücksichtigt man die Besonderheiten der Organisation der Cubomeduse (p. 498), so wird unmittelbar klar, daß auch unter dem Gesichtspunkt der Medusenstruktur eine Einordnung in die Hydrozoa nicht möglich ist. Die Entstehung der Hydroidmeduse als Glockenkernmeduse durch einen seitlichen Knospungsvorgang und als Neubildung ist ein ganz wesentliches Merkmal, auf das hier hingewiesen werden muß, so daß grundlegende Unterschiede zur Medusenentstehung bei Tripedalia bestehen.

So bleibt nur die Möglichkeit, die Cubozoa in den Rang einer eigenen Klasse zu erheben, die zwischen den Scypho- und Hydrozoa einzuordnen ist. Die zwanglose Erklärung für gewisse Gemeinsamkeiten mit den Scyphozoa sowohl in der Polypen- 
wie in der Medusengeneration ist die, daß beide Klassen auf gemeinsame Vorfahren zurückgehen und daß die Scyphozoa diesen näher stehen als die Cubozoa.

Abschließend müssen noch interessante Befunde erwähnt werden, die BERGER (1900) bei der Auswertung der Versuchsprotokolle ConANTs nach dessen frühem Tod mitgeteilt hat. Die Untersuchungen Conants betreffen das Verhalten der Medusen von Carybdea xaymacana (heute C. marsupialis) bei Hell- und Dunkelexperimenten und bei verschiedenen Ex- und Incisionsversuchen zur Ermittlung der Aktions- und Reaktionszentren für die Koordination der Schwimmbewegungen. Bei der Auswertung der Versuchsergebnisse kommt BERger (p. 23) zu dem für uns sehr interessanten Resultat: "Finally... Charybdea seems to occupy, physiologically, a position intermediate between the Hydromedusae and the Scyphomedusae." Wenn auch zu prufen ist, ob diese Schlußfolgerung dem Ergebnis von Untersuchungen mit modernen Methoden standhält, so ist sie doch deswegen besonders bemerkenswert, weil sie in einem speziellen Aspekt die Stellung der Cubozoa zwischen den Scyphozoa und Hydrozoa vorweggenommen und bestätigt hat, obwohl damals die Scyphozoennatur der Cubomedusen noch nahezu unangefochten war.

\section{DIAGNOSEN}

\section{Tripedalia cystophora (Cubozoa, Fam. Carybdeidae)}

Polyp solitär, klein, mit radialsymmetrischem, sackförmigem Körperbau, Gastralraum also einheitlich, ohne Septen; 6-11 solide, capitate Tentakel in einem Kranz angeordnet, darüber große, rüsselförmige Proboscis. Form des Körpers variabel, meist flaschenförmig bis stumpfkegelig mit wenig verschmälerter Basis, die von kleinem, strukturlosem Peridermbecher umgeben ist; asexuelle Vermehrung durch laterale Polypenknospen, die nach der Ablösung eine Kriechphase durchmachen. Erwachsener Polyp zur Ortsveränderung und Encystierung befähigt. Medusenbildung durch vollständige Metamorphose des Polypen in eine Meduse. Jungmeduse mit 4 interradialen Einzeltentakeln ohne Pedalien. Tricnidom von basitrichen Haplonemen, holotrichen Haplonemen und heterotrichen mikrobasischen Eurytelen.

\section{Klasse Cubozoa}

Cnidaria mit Generationswechsel, Polyp klein, solitär mit radialsymmetrischem Körperbau und einheitlichem Gastralraum. Medusenbildung durch vollständige Metamorphose des Polypen; Medusen mit glocken- oder würfelförmigem Schirm, einheitlichem Mundrohr, Velarium und 4 durch Septen unvollständig verschlossenen Gastraltaschen; Gonaden entodermal.*

* Anmerkung: Es ist damit zu rechnen, daß die Diagnosen noch ergänzt werden müssen, wenn die Ergebnisse der histologischen Untersuchungen von CHAPMAN publiziert werden. 


\section{ZUSAMMENFASSUNG}

1. Die Cubomedusen wurden seit Haeckel (1880) zu den Scyphozoa gerechnet. Dadurch, daß es erstmals gelungen ist, im Kulturversuch den vollständigen Lebenszyklus einer Art zu reproduzieren, hat sich gezeigt, daß diese Einordnung nicht länger beibehalten werden kann.

2. Die aus der Literatur bekannten Tatsachen über die Entwicklung der Cubomedusen werden kurz rekapituliert. Bei zwei Arten war die Entwicklung der Planulae zu Primärpolypen beobachtet worden. Obwohl diese nicht zur Weiterentwicklung kamen, war an dem Vorhandensein einer Polypengeneration nicht zu zweifeln.

3. Im Anschluß an die gelungene Aufzucht der Primärpolypen der karibischen Art Tripedalia cystophora aus Planulae konnten sämtliche Entwicklungsphasen beobachtet und die Lebensgeschichte dieser Art vollständig aufgeklärt werden.

4. Entwicklung, Wachstum, Morphologie und Anatomie des Polypen werden beschrieben. Der sessile, solitäre, kleine Polyp $(0,6-1,0 \mathrm{~mm})$ ist radialsymmetrisch gebaut und besitzt einen einfachen, sackförmigen Körper mit einheitlichem Gastralraum ohne Septen oder andere tetramere Strukturen. Die Zahl der soliden, in einem Kranz angeordneten capitaten Tentakel beträgt 6 bis 11. Der Mundkonus ist groß, muskulös und dadurch rüsselähnlich. Der Basalteil des in der Form variablen Körpers ist mit einem kleinen, zartwandigen und strukturlosen Peridermbecher umgeben.

5. Mit einem Alter von etwa 5-6 Wochen beginnt der Polyp, sich asexuell durch seitlich gebildete, sich ablösende Polypenknospen zu vermehren. Die Knospungsvorgänge werden kurz beschrieben.

6. Der eben abgelöste Sekundärpolyp besitzt 2 bis 3 Tentakel und macht eine Kriechphase durch. Der abgeflachte, langgestreckte Körper kriecht mit dem Kopfteil voran, wobei ein maximal ausgestreckter Tentakel wie eine Suchantenne vorangetragen wird. Nach 2 bis 3 Tagen heftet sich der Kriechpolyp fest und nimmt die normale Form an.

7. Verhaltensweisen des Polypen bei der Ennährung, Ortsveränderung und Encystierung werden beschrieben. Der erwachsene Polyp hat die Fähigkeit, sich vom Substrat abzulösen und kriechend einen neuen Anheftungsort aufzusuchen. Er nimmt dabei die für den jungen Sekundärpolypen in der Kriechphase typische Form an. Ferner ist der Polyp in der Lage, sich zu encystieren und in ein inaktives Ruhestadium umzuwandeln. Diese Fähigkeiten werden als Reaktionen auf Umweltveränderungen gedeutet.

9. Die Bildung der Meduse geschieht durch die vollständige Metamorphose des Polypen in eine und nur eine Meduse.

10. Die äußerlich erkennbaren Einzelvorgänge der Metamorphose werden beschrieben. Sie setzt damit ein, daß der Körper des Polypen durch 4 Längsfalten tetramer wird und in der Aufsicht 4 Quadranten aufweist. Die Tentakel werden zu 4 Gruppen zusammengezogen, von denen je eine einem Quadranten zugeordnet wird. Die Endabschnitte der Tentakel werden resorbiert, während sich die Basalteile in die 4 perradialen Sinnesorgane (Rhopalia) der Meduse umwandeln. Die 4 interradialen Primärtentakel der Meduse entstehen als Neubildung zwischen den Sinnes- 
organen. Die im Inneren verlaufenden Strukturänderungen, die der künttigen genaueren anatomisch-histologischen Analyse bedürfen, bestehen in der Bildung der Gastraltaschen aus Entodermfalten so wie in der Entstehung des Subumbrellarraumes aus einer ektodermalen Einsenkung im Umkreis des Mundkonus. Der Basalteil des Polypen wird zuletzt in die Umwandlung einbezogen und wandelt sich in den Apikalteil der Meduse um. Nach beendeter Metamorphose schwimmt die Jungmeduse davon und läßt am Entstehungsort nur den leeren Peridermbecher zurück. Der Prozeß der Metamorphose dauert bei $25^{\circ}$ bis $27^{\circ} \mathrm{C} 5$ bis 6 Tage.

11. Morphologie und Struktureigenschaften der Jungmeduse werden dargestellt.

12. Tripedalia cystophora hat ein Tricnidom von basitrichen Haplonemen, holotrichen Haplonemen, heterotrichen mikrobasischen Eurytelen. Die Einzelheiten der Nesselzellausstattung der Planula und der beiden Generationen werden beschrieben.

13. Die Verbreitung der Meduse und die Okologie beider Generationen werden kurz umrissen.

14. Die Metamorphose des Polypen von Tripedalia in die Meduse kann als Bestätigung für die alte, auf der Homologie der Strukturen beruhende Auffassung dienen, daß die Meduse evolutionistisch ein abgelöster, in Anpassung an die freischwimmende Lebensweise umgewandelter Polyp ist.

15. Ein Teilvorgang der Metamorphose, die Umwandlung der Tentakelbasen in die Sinnesorgane, steht in Einklang mit der früheren theoretischen Annahme, daß bei den Scyphomedusen die Sinnesorgane evolutionistisch als umgewandelte Tentakel zu betrachten sind.

16. Die Untersuchungsergebnisse und der Vergleich mit den Scyphozoa und Hydrozoa unter den verschiedenen Aspekten führen zu der Schlußfolgerung, daß die Cubozoa als neue Klasse zwischen den Scyphozoa und den Hydrozoa eingeordnet werden müssen.

17. Die Diagnose des Polypen von Tripedalia und die Klassendiagnose werden gegeben.

Danksagungen. Herrn Prof. CH. E. Cutress, Department of Marine Sciences, University of Mayagüez, Puerto Rico, USA, möchte ich für die großzügige und vielseitige Hilfe bei der Materialbeschaffung sowie für die finanzielle Hilfe und warmherzige Gastfreundschaft während eines Studienaufenthaltes an der Meeresstation La Parguera im November/Dezember 1971 meinen tiefempfundenen Dank aussprechen. Ebenso bin ich der Deutschen Forschungsgemeinschaft für eine Reisebeihilfe und die langjährige Förderung meiner Arbeiten zu größtem Dank verpflichtet. Herrn Prof. D. M. Chapman, Halifax, Canada, danke ich für die gute Zusammenarbeit wie auch besonders dafür, daß er mir die Ergebnisse seiner histologischen Untersuchungen im Manuskript seiner in Vorbereitung befindlichen Arbeit vermittelte. Danken möchte ich auch meiner Mitarbeiterin Frl. S. Hogreve, Hamburg, die die langfristigen Kulturarbeiten stets zuverlässig und sorgfältig ausgeführt hat.

\section{ZITIERTE LITERATUR}

Barnes, J. H., 1966. Studies on three venomous Cubomedusae. In: The Cnidaria and their evolution. Ed. by W. J. Rees. Acad. Press, London, $307-332$ (Symp. zool. Soc. Lond. 16). 
Berger, E. W., 1900. Physiology and histology of the Cubomedusae, including Dr. F. S. Conant's notes on the physiology. Mem. biol. Lab. Johns Hopkins Univ. 4, 1-84.

Boullon, J., 1974. Sur la structure de Paracoryne buvei, PiCARd 1957 (Coelenterata, Hydrozoa, Athecata). Mém. Acad, r. Belg. Cl. Sci. 18, 1-44.

CAlder, D. R. \& Peters, E. C., 1975. Nematocysts of Chiropsalmus quadrumanus with comments on the systematic status of the Cubomedusae. Helgoländer wiss. Meeresunters. 27, 364-369.

Chapman, D. M., 1974. Cnidarian histology. In: Coelenterate biology. Ed. by L. Muscatine and H. M. Lenhoff. Acad. Press, New York, 512 pp.

-.- Structure of the cubopolyp Tripedalia cystopbora. (In preparation.)

- \& Werner, B., 1972. Structure of a solitary and a colonial species of Stephanoscyphus (Scyphozoa, Coronatae) with observations on periderm repair. Helgoländer wiss. Meeresunters. 23, 393-421.

Claus, C., 1883. Untersuchungen über die Organisation und Entwicklung der Medusen. Tempsky, Prag; Freytag, Leipzig, 96 pp.

Cleland, J. B. \& Southcott, R. V., 1965. Injuries to man from marine invertebrates in the Australian region. Spec. Rep. Ser. natn. Hlth. med. Res. Coun., Canberra 12, 1-182.

Conant, F. S., 1898. The Cubomedusae. Mem. biol. Lab. Johns Hopkins Univ, 4, 1-61.

HAACKE, W., 1887. Die Scyphomedusen des St. Vincent Golfes. Jena. Z. Naturw. 20, 588-637.

HAECKEL, E., 1880. Das System der Medusen. 1, (2) System der Acraspeden. Fischer, Jena, $361-672$.

Halstead, B. W., 1965. Poisonous and venomous marine animals of the world. U. S. Gov. Print. Off., Washington, D. C., 1, 297-371.

Kingston, C. W. \& Southcott, R. V., 1960. Skin histopathology in fatal jellyfish stinging. Trans. R. Soc. trop. Med. Hyg. 54, 373-384.

Kramp, P. L., 1961. Synopsis of the medusae of the world. J. mar. biol. Ass. U. K. 40, 1-469.

Krumbach, T., 1924. Scyphozoa. Handb. Zool. 1, 522-686.

KuHL, G., 1947. Zeitrafferfilm-Untersuchungen über den Polypen von Craspedacusta sowerbii (Ungeschlechtliche Fortpflanzung, Okologie und Regeneration). Abh. senckenb. naturforsch. Ges. 473, 1-72.

Mayer, A. G., 1910. Medusae of the world. Publs. Carnegie Instn 109, 1-735.

Orada, Y. K., 1927. Note sur l'ontogénie de Carybdea rastonii HAaCkE. Bull. biol. Fr. Belg. 61, 241-249.

PAPENFUss, E. J., 1936. The utility of the nematocysts in the classification of certain Scyphomedusae. Acta Univ. Lund. (Avd. 2) 31, 1-26.

Rensch, B., 1959. Die phylogenetische Abwandlung der Ontogenese. In: Die Evolution der Organismen. Hrsg. G. Heberer. Fischer, Sturtgart, 1, 103-130.

Russell, F. S., 1970. The Medusae of the British Isles. Cambridge Univ. Press, London, 2, $1-284$.

Salvini Plawen, L., 1966. Zur Kenntnis der Cnidaria des nordadriatischen Mesopsammon. Veröff. Inst. Meeresforsch. Bremerh. (Sonderbd.) 2, 165-186.

Schmidt, H., 1969. Die Nesselkapseln der Aktinien und ihre differentialdiagnostische Bedeutung. Helgoländer wiss. Meeresunters. 19, 284-317.

- 1972. Die Nesselkapseln der Anthozoen und ihre Bedeutung für die phylogenetische Systematik. Helgoländer wiss. Meeresunters. 23, 422-458.

Sifostak, S., 1974. The complexity of Hydra: homeostasis, morphogenesis, controls and integration. Quart. Rev. Biol. 49, 287-310.

SoutrcotT, R. V., 1967. Revision of some Carybdeidae (Scyphozoa: Cubomedusae), including a description of the jellyfish responsible for the "Irukandji syndrome". Aust. J. Zool. 15, 651-671.

- \& Kingston, C. W., 1959. Lethal jellyfish stings: a study in "sea wasps". Med. J. Aust. 1, 443-444.

Srrasny, G., 1926. Über einige Scyphomedusen von Puerto Galera, Mindoro (Philippinen). Zool. Meded., Leiden 7, 239-248. 
Thiel, M. E., 1936. Scyphomedusae: Cubomedusae. Bronn's K1. Ordn. Tierreichs 2 (2), $173-$ 307.

UCHIDA, T., 1929. Studies on the Stauromedusae and Cubomedusae, with special reference to their metamorphosis. Jap. J. Zool. 2, 103-193.

- 1954. Distribution of Scyphomedusae in Japanese and its adjacent waters. J. Fac. Sci Hokkaido Univ. (Zool.) 12, 209-219.

- 1969. The interrelationships of Scyphozoan class. Bull. biol. Stn Asamushi 13, 247-250.

-. 1970. Revision of Japanese Cubomedusae. Publs Seto mar. biol. Lab. 17, 289-297.

- 1973. The systematic position of the Stauromedusae. Publs Seto mar. biol. Lab. 20, 133-139.

W'EILL, R., 1934. Contributions à l'étude des Cnidaires et de leurs nématocystes. 1, 2. Trav. Stn zool. Wimereux 10-11, 1-701.

Werner, B., 1950. Weitere Beobachtungen über das Auftreten der Meduse Gonionemus murbachi Mayer im Sylter Wattenmeer und ihre Entwicklungsgeschichte. Verh. dt. zool. Ges. $1950,129-151$.

- 1965. Die Nesselkapseln der Cnidaria, mit besonderer Berücksichtigung der Hydroida. I. Klassifikation und Bedeutung für die Systematik und Evolution. Helgoländer wiss. Meeresunters. 12, 1-39.

- 1966. Stephanoscyphus (Scyphozoa, Coronatae) und seine direkte Abstammung von den fossilen Conulata. Helgoländer wiss. Meeresunters. 13, 317-347.

- 1967. Morphologie, Systematik und Lebensgeschichte von Stepbanoscyphus (Scyphozoa, Coronatae) sowie seine Bedeutung für die Evolution der Scyphozoa. Zool. Anz. (Suppl.) 30, 297-319.

- 1970. Weitere Untersuchungen über die Entwicklungsgeshichte von Stephanoscyphus (Scyphozoa, Coronatae) und seine Bedeutung für die Evolution der Scyphozoa. Zool. Anz. (Suppl.) 33, 159-165.

- 1971. Neue Beiträge zur Evolution der Scyphozoa und Cnidaria. Acta Salmant. (Ciencias) 36, 223-244.

-- 1973a. Spermatozeugmen und Paarungsverhalten bei Tripedalia cystopbora (Cubomedusae). Mar. Biol. 18, 212-217.

- 1973b. New investigations on systematics and evolution of the class Scyphozoa and the phylum Cnidaria. Publs Seto mar. biol. Lab. 20, 35-61.

-- \& Chapman, D. M. Muscular and nervous system of the cubopolyp (Cnidaria). (In preparation.)

- Cutress, Ch. E. \& Studebaker, J. P., 1971. Life cycle of Tripedalia cystophora Conant (Cubomedusae). Nature, Lond. 232, 582-583.

Wrtterbach, C. R., 1968. The dynamics of stolon elongation in the hydroid, Campanulariat flexuosa. J. exp. Zool. 167, 333-352.

Anschrift des Autors: Dr. B. Werner

Biologische Anstalt Helgoland (Zentrale)

2 Hamburg 50

Palmaille 9

Bundesrepublik Deutschland 